\title{
Research Paper \\ Pattern of Outpatient Health Service Utilization by Older People in Iran
}

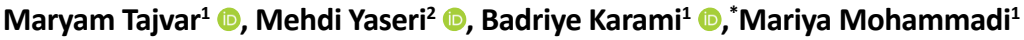

1. Department of Health Management and Economics, School of Public Health, Tehran University of Medical Sciences, Tehran, Iran 2. Department of Epidemiology and Biostatistics, School of Public Health, Tehran University of Medical Sciences, Tehran, Iran.

\begin{tabular}{|c|c|}
\hline $\begin{array}{l}\text { Use your device toscan } \\
\text { and read the article online }\end{array}$ & deat on: Tajvar M, Yaseri M, Karami B, Mohammadi M. [Pattern of Outpatient Health Service Utilization by Older People in \\
\hline 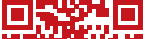 & Iran (Persian)]. Iranian Journal of Ageing. 2021; 15(4):410-427. https://doi.org/10.32598/sija.15.4.2921.1 \\
\hline 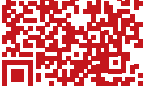 & dolishttps://doi.org/10.32598/sija.15.4.2921.1 \\
\hline
\end{tabular}

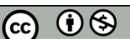

Received: 20 Feb 2020 Accepted: 08 Jun 2020 Available Online: 01 Jan 2021

Key words: Need, Utilization, Outpatient health services, Elderly, Iran

\section{A B STRACT}

Objectives Considering the rapid growth of Iran's elderly population with consequent increase in the costs of health services, it is necessary to be aware of the pattern of outpatient health service utilization, in the elderly for resource allocation and health planning. This study aims to determine the pattern of outpatient service utilization for the elderly in Iran and explore determinant factors.

Methods \& Materials This is a cross-sectional study using secondary analysis method and the data from 2015 National Study of Health Service Utilization. Study population consists of older people aged $\geq 60$ years. Of these, 8205 were selected as study samples. The data were collected using personal and household questionnaires collecting information on subjects' need for, referral to, utilization from, and satisfaction with outpatient services. Logistic regression analysis was used to identify factors related to the need, referral, benefit, and satisfaction with the received outpatient services.

Results Out of 8205 participants, 3172 (39\%) reported the need for outpatient services, of which $66 \%$ referred for services; of these, $98 \%(\mathrm{~N}=2060)$ benefited outpatient services. Females, older subjects, villagers, unmarried and illiterate subjects were more in need of outpatient services, but their referrals to receive the services were not more than those of other groups. Lack of basic insurance, supplementary insurance, and a personal care had a significant impact on reducing the number of subjects referred to receive outpatient services. Inability to pay treatment costs (30\%), self-treatment (28\%) and lack of proper insurance coverage (13\%) were the most important reasons for not referring to receive outpatient services. The highest satisfaction was related to the behavior of physicians and medical staff and the lowest satisfaction was related to the cost of outpatient services.

Conclusion Although the use of outpatient health services should be based on the need for these services, the present study showed that the older people with higher socio-economic status had higher utilization from the services in Iran. Therefore, there is an inequality in access to outpatient services in the elderly. The reasons for not using outpatient services and dissatisfaction with these services should be seriously considered by health policy makers.

\section{Extended Abstract}

\section{Introduction}

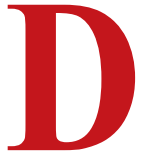

ue to the rapid growth of Iran's elderly population, the demand for health services and the rate of health costs are increasing in this country. The elderly are major consumers of health services and are put a heavy financial burden on the health system and insurance organizations $[1,7-10]$. In order to be prepared to respond to the growing health needs of the elderly and to face the challenges ahead, it is necessary to be aware of the status and patterns of need and utilization for health services in the elderly to allocate resources in

\section{* Corresponding Author:}

\section{Mariya Mohammadi, MSc.}

Address: Department of Health Management and Economics, School of Public Health, Tehran University of Medical Sciences, Tehran, Iran

Tel: +98 (21) 42933055

E-mail: maria.mohammadi1395@gmail.com 
this area. Health service utilization studies help to identify related underlying factors and facilitators or barriers to utilization and to determine the appropriateness of the volume and quality of provided care $[14,15]$. This study aims to investigate the pattern of outpatient health service utilization in the elderly in Iran, their level of satisfaction with the services, and the underlying factors related to the utilization and satisfaction.

\section{Methods \& Materials}

This is a secondary quantitative study with cross-sectional design using the primary data of the "National Study of Health Service Utilization" conducted in 2015 by the National Institute for Health Research and the Statistics Research Institute. The study population consists of all older people aged $\geq 60$ years in Iran. Of these, 8205 were selected by three-stage random sampling method from the provinces, cities and villages. Data collection tool in this study was two structured questionnaires, one was a household questionnaire completed by the head of the household and the other was a personal questionnaire only for family members who at the time of completing the questionnaire expressed a need for outpatient services during the past two weeks. For those who received the services, a questionnaire measuring the utilization and satisfaction with the received services was completed. The raw data of this study were first entered into Excel software for data cleaning and data management, and the accuracy and consistency of the data were checked and confirmed. Due to the fact that the number of missing data was very small, the features were ignored for those samples when analyzing the data. Finally, the data were entered into SPSS17 software for statistical analysis. Descriptive statistics such as mean, frequency and percentage were used for describing data, and multilevel logistic regression analysis in four models was used to examine the factors related to the need, referral, utilization, and satisfaction for outpatient services. To show the distribution of outpatient services for the elderly in Iran, a map prepared in GIS software was used.

\section{Results}

In this study, out of 8205 participants, 3172 (39\%) reported the need for outpatient services, of which $66 \%$ referred for services; of these, 98\% $(n=2060)$ benefited from outpatient services. There was a relatively high distribution among the provinces of Iran in terms of benefiting from outpatient health services compared to the need for these services. People who did not refer to receive the outpatient services despite the need for them $(n=1068)$ were asked about the reasons for not referring. Inability to afford (30\%), self-treatment (28\%) and lack of proper insurance coverage (13\%) were the most important reasons. Overall satisfaction of $54 \%$ of service recipients was low-to-moderate; in others $(46 \%)$, it was relatively high. Older, illiterate and rich people were more dissatisfied with the received services than others.

The factors related to the need for outpatient services, referring to receive the services, using the services, and satisfaction with the services are presented in Table 1 categorized into 4 models. In the first model, the need for outpatient services had a significant relationship with gender, age, place of residence, marital status, literacy, basic insurance and owning a car $(\mathrm{P}<0.05)$. The second model showed that, although females, older ones, villagers and the unmarried were more in need of outpatient services, their referrals to receive the services were not more than those of other groups. Moreover, while the illiterate needed more health services, but the number of literate subjects referred to receive services was significantly higher.

Lack of basic insurance, supplementary insurance, and a personal car had a significant impact on reducing the number of elderly people referred to receive outpatient services. In the third model, considering that $98 \%$ of the subjects were able to receive the needed services, their characteristics did not show a relationship with the health service utilization. In the fourth model, there was a significant relationship between the satisfaction level and the age of $>70$ years, place of residence, marital status and literacy such that the elderly over 70 years of old, living in rural areas and unmarried had significantly less satisfaction than others.

\section{Conclusion}

Although the use of health services should be based on the need for these services, the present study showed that the socio-economic status of older people is an important determinant of access to and use of outpatient health services by them. The most common reasons for referring to receive outpatient services included inability to pay the expenses, self-treatment, and lack of health insurance. Therefore, it is expected that by taking measures to improve the living conditions of the older people, increasing their health insurance coverage, integration of insurance organizations, and promoting the Family Physician Program, the use of outpatient services by the elderly can be increased. It is necessary to identify the effective variables and take measures to improve their status. The results of this study can be helpful with reforming the health system and how resources are allocated to this age group. 
Table 1. Results of logistic regression analysis to determine the factors related to the need for, referral to, utilization of, and satisfaction with outpatient health services

\begin{tabular}{|c|c|c|c|c|c|c|c|c|c|}
\hline \multicolumn{2}{|c|}{ Variables } & \multicolumn{2}{|c|}{$\begin{array}{c}\text { Model 1, Need for Outpa- } \\
\text { tient Services }\end{array}$} & \multicolumn{2}{|c|}{$\begin{array}{l}\text { Model 2, Referral to Re- } \\
\text { ceive Outpatient Services }\end{array}$} & \multicolumn{2}{|c|}{$\begin{array}{c}\text { Model 3, Utilization of } \\
\text { Outpatient Services }\end{array}$} & \multicolumn{2}{|c|}{$\begin{array}{c}\text { Model 4, Satisfac- } \\
\text { tion With Outpatient } \\
\text { Services }\end{array}$} \\
\hline & & $\mathbf{P}$ & OR (95\% Cl) & $\mathbf{P}$ & OR (95\% Cl) & $\mathbf{P}$ & OR (95\% Cl) & $\mathbf{P}$ & OR (95\% Cl) \\
\hline \multirow{2}{*}{ Gender } & Male & & 1 & & 1 & & 1 & & 1 \\
\hline & Female & $0.001<$ & $1.51(1.67-1.36)$ & 0.11 & $1.14(0.96-1.36)$ & 0.82 & $0.92(0.47-1.81)$ & 0.50 & $0.93(0.75-1.15)$ \\
\hline \multirow{3}{*}{ Age (y) } & $60-64$ & & 1 & & 1 & & 1 & & 1 \\
\hline & $65-69$ & $0.001<$ & $1.22(1.10-1.36)$ & 0.38 & $0.92(0.76-1.10)$ & 0.91 & $0.96(0.47-1.95)$ & 0.27 & $0.88(0.69-1.10)$ \\
\hline & $70<$ & $0.007<$ & $1.18(1.04-1.34)$ & 0.86 & $0.98(0.80-1.20)$ & 0.18 & $0.51(0.19-1.37)$ & 0.01 & $0.73(0.56-0.94)$ \\
\hline \multirow{2}{*}{$\begin{array}{l}\text { Place of } \\
\text { residence }\end{array}$} & Urban areas & & 1 & & 1 & & 1 & & 1 \\
\hline & Rural areas & 0.02 & $1.12(1.01-1.24)$ & 0.63 & $1.04(0.88-1.22)$ & 0.17 & $0.56(0.81-3.00)$ & 0.03 & $0.78(0.63-0.97)$ \\
\hline \multirow{2}{*}{$\begin{array}{l}\text { Marital } \\
\text { status }\end{array}$} & Married & & 1 & & 1 & & 1 & & 1 \\
\hline & Unmarried & 0.01 & 1.15 (1.02-1.29) & 0.36 & 0.91 (0.76-1.10) & 0.14 & $1.77(0.81-3.84)$ & 0.05 & $0.78(0.62-1.00)$ \\
\hline \multirow{2}{*}{ Literacy } & literate & & 1 & & 1 & & 1 & & 1 \\
\hline & Illiterate & 0.04 & $1.11(1.00-1.24)$ & 0.005 & $0.76(0.63-0.92)$ & 0.15 & $0.56(0.25-1.25)$ & 0.01 & $1.32(1.04-1.66)$ \\
\hline \multirow{2}{*}{$\begin{array}{l}\text { Basic insur- } \\
\text { ance }\end{array}$} & Yes & & 1 & & 1 & & 1 & & 1 \\
\hline & No & 0.05 & 0.73 (0.53-1.00) & 0.007 & 0.59 (0.41-0.87) & 0.53 & $1.90(0.25-14.32)$ & 0.67 & $1.12(0.56-1.94)$ \\
\hline \multirow{2}{*}{$\begin{array}{l}\text { Supple- } \\
\text { mentary } \\
\text { insurance }\end{array}$} & Yes & & 1 & & 1 & & 1 & & 1 \\
\hline & No & 0.79 & $0.01(0.90-1.13)$ & 0.03 & $0.81(0.67-0.98)$ & 0.10 & 0.47 (0.19-1.17) & 0.80 & $0.97(1.22-0.77)$ \\
\hline \multirow{2}{*}{$\begin{array}{c}\text { Home } \\
\text { ownership }\end{array}$} & Yes & & 1 & & 1 & & 1 & & 1 \\
\hline & No & 0.84 & $0.98(0.83-1.15)$ & 0.12 & $0.81(0.63-1.05)$ & 0.36 & $1.93(0.45-8.19)$ & 0.08 & $1.33(0.96-1.86)$ \\
\hline \multirow{2}{*}{$\begin{array}{l}\text { Car owner- } \\
\text { ship }\end{array}$} & Yes & & 1 & & 1 & & 1 & & 1 \\
\hline & No & $>0.001$ & 1.21 (1.09-1.34) & 0.01 & $0.78(0.65-0.94)$ & 0.09 & $0.48(0.20-1.13)$ & 0.74 & $1.03(0.83-1.29)$ \\
\hline
\end{tabular}

S A L M M N D D
IRANIAN JOURNAL OF AGEING

\section{Ethical Considerations}

Compliance with ethical guidelines

This study was approved by the Research Ethics Committee of Tehran University of Medical Sciences (Code: IR.TUMS.SPH.REC.1397.4982).

Funding

This study was extracted from Msc. thesis of the last author at Department of Epidemiology and Biostatistics, School of Public Health, Tehran University of Medical Sciences, Tehran. Also, this study was supported by Tehran University of Medical Sciences.
Authors' contributions

All authors contributed equally in preparing this paper.

Conflicts of interest

The authors declared no conflict of interest.

Acknowledgements

The authors would like to thank School of Public Health and Statistics Research Institute of Iran for their cooperation. 


\title{
التَوى بهرهمندى سالمندان از خدمات سريايى سلامت در ايران

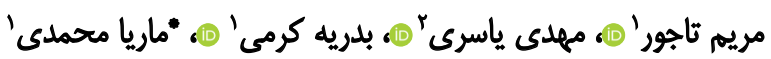 \\ I. تمروه علوم مديريت واقتصاد سلامت، دانشكده بهداشت، دانشعاه علوميزئشكى تهران، تهران، ايران. \\ r. كروه إييدميولورى و آمار زيستى، دانشكده بهـاشت، دانشكاه علوميزشكى تهران، تهران، ايران.
}

\begin{abstract}
حكSי

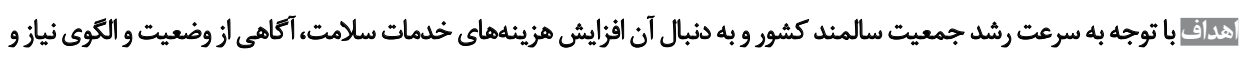

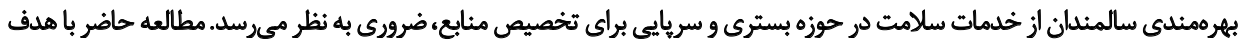

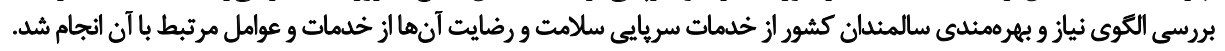

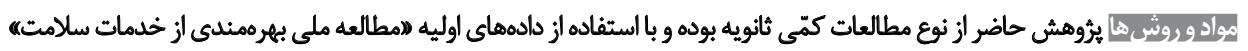

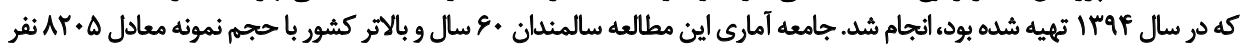

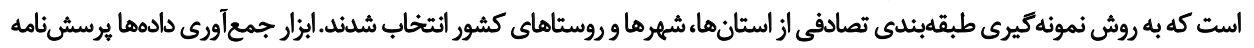

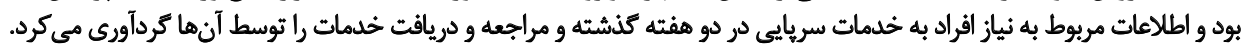

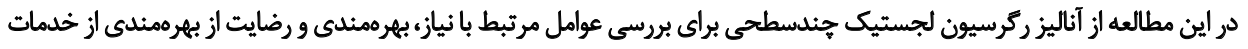
سرياييى استفاده شد.

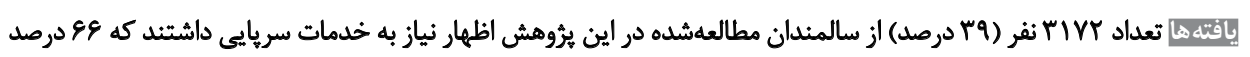

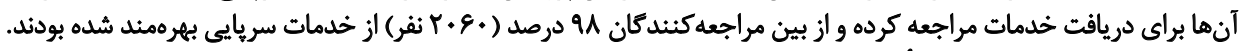

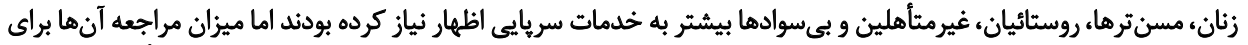

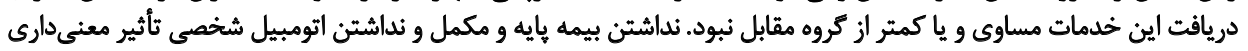

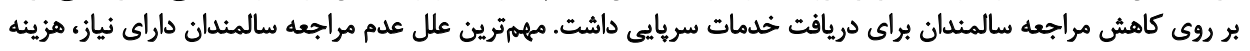

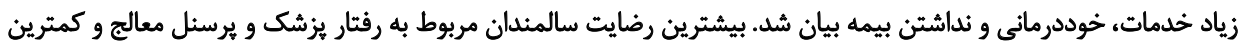

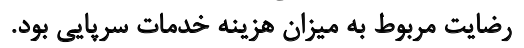

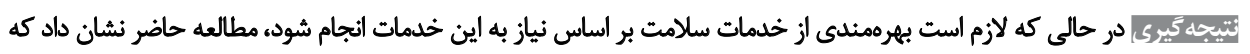

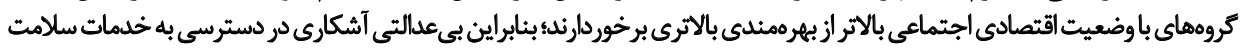

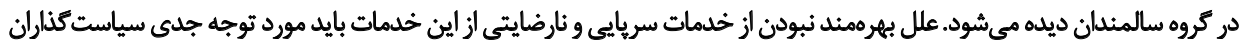
سلامت قرار كيرد.
\end{abstract}

تاريخ دريافت: اسفند

تاريخ بذيرش: 19 خرداد

تاريخ انتشار: זו دى

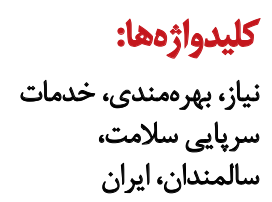

كليدواروها:

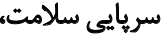
سالمندان، ايران

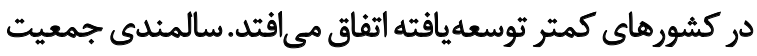

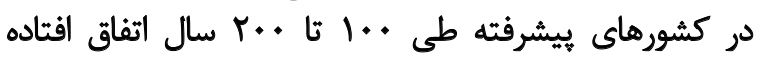

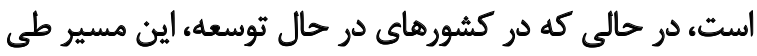

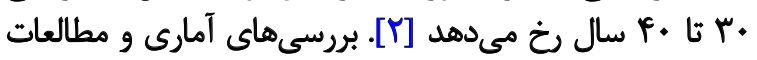

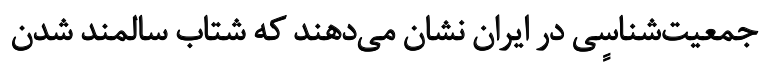

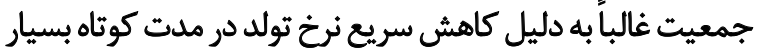

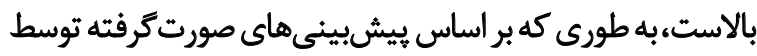

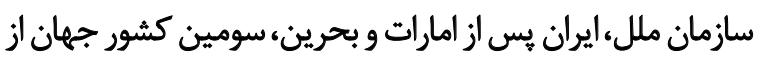

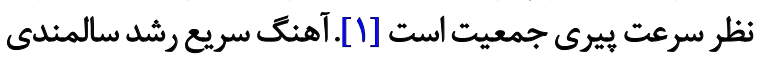

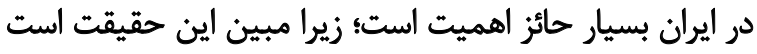

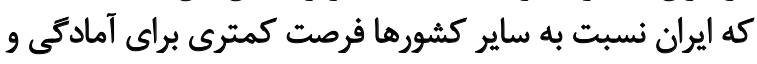

طي جند دها اخير، توسعه اقتصادى و اجتماعى، بهبود بهادي

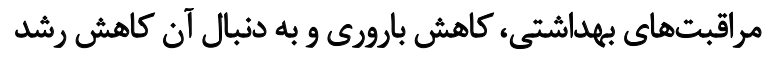

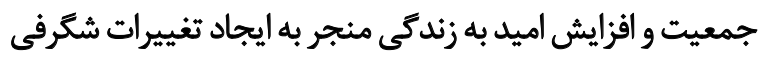

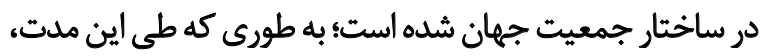

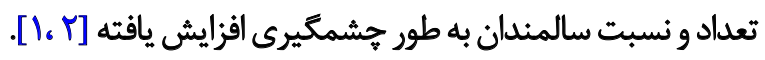

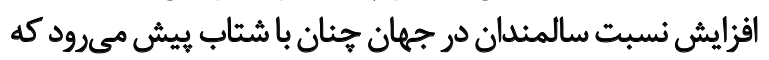

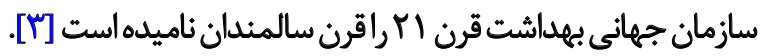

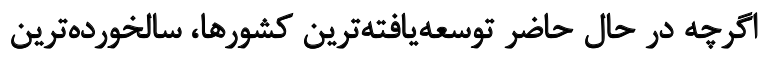

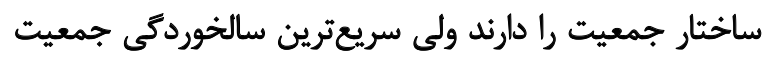

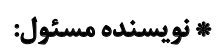

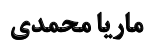

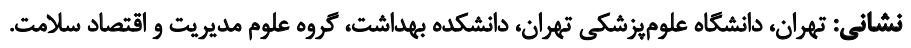
تلفن: يست الكترونيكي: maria.mohammadi1395@gmail.com 
و مديريت بهتر خدمات سلامت به نتايج بهترى در سلامت جامعه

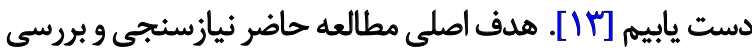

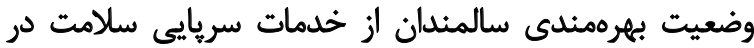

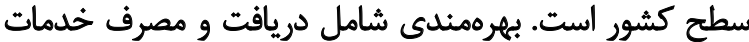

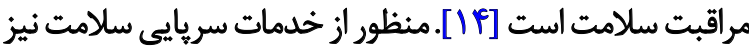

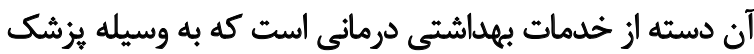

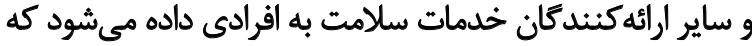

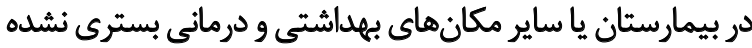

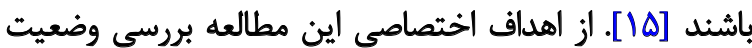

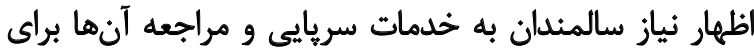

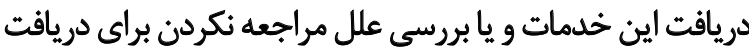

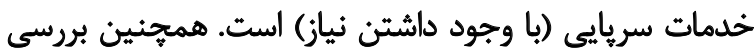

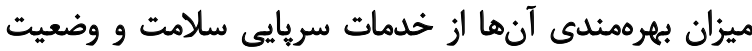

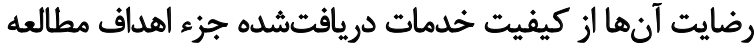

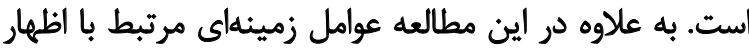

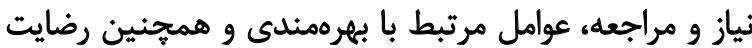
سالمندان بهرهمندشده از خدمات سريطي بايى تحليل شده است.

تاكنون مطالعات متعددى روى بهرهمندى از خدمات سلامت

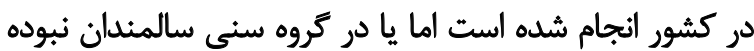

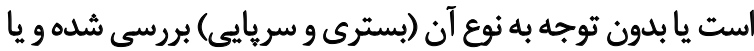

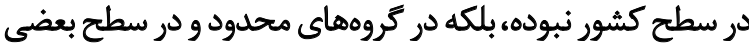

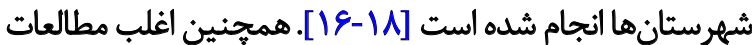

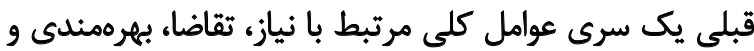

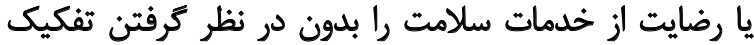

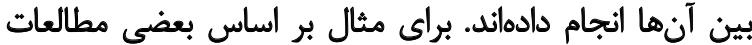

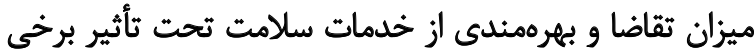

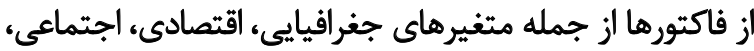

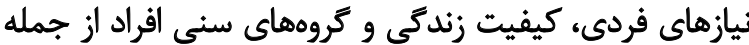

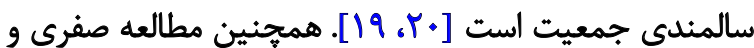

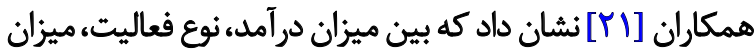

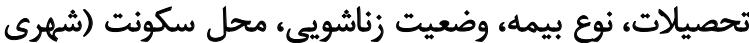

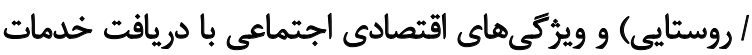

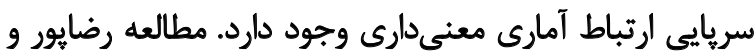

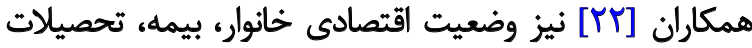

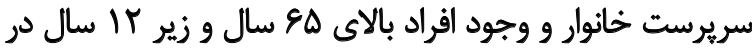

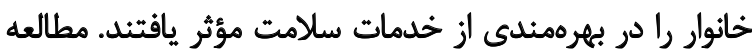

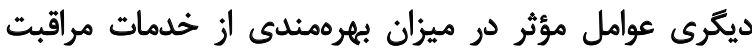

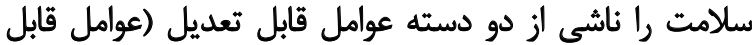

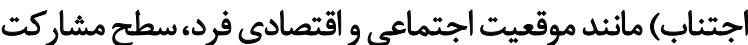

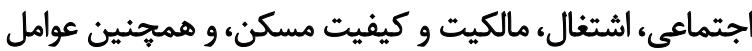

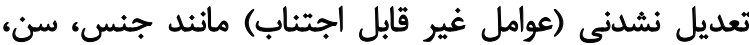

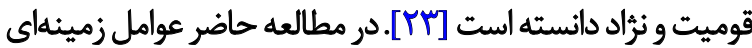

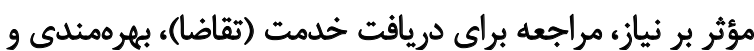

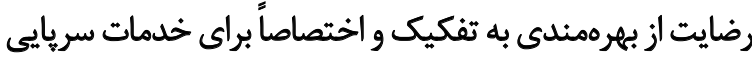

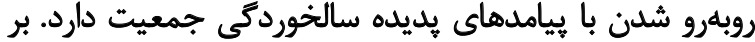

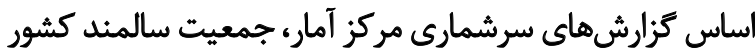

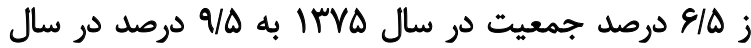

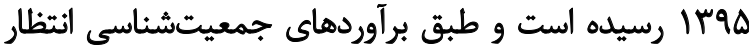

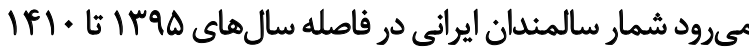

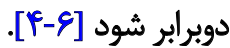

كرجها وقوع بديده سالمندى جمعيت، كه به دنبال افزايش

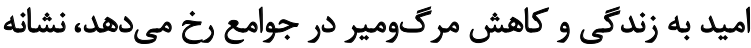

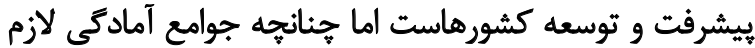

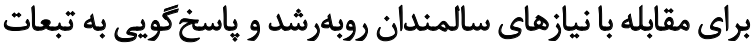

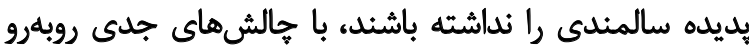

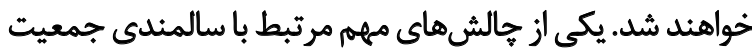

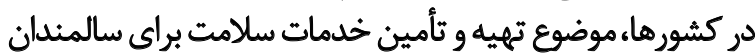

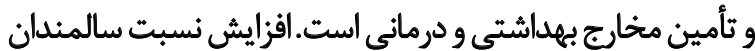

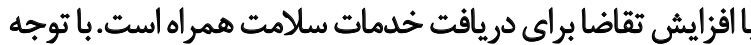

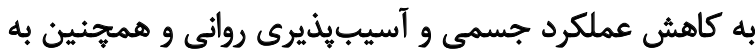

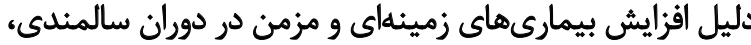

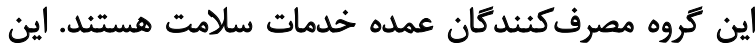

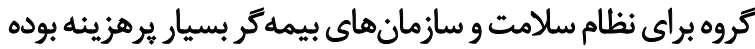

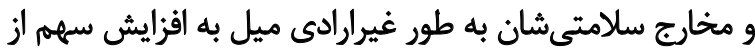

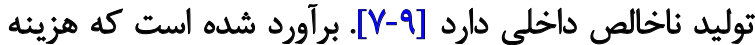

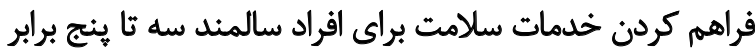

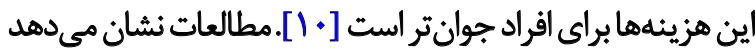

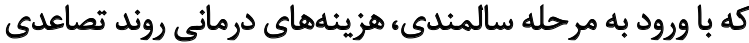

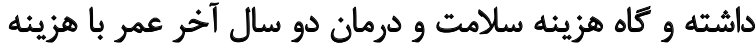

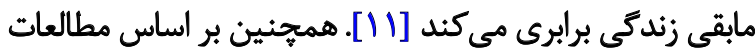

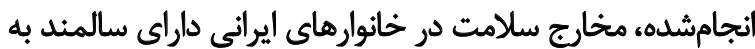

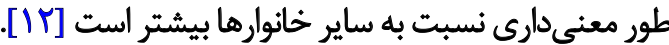
بنابراين بيشبينى مىشود كه با افزايش تدريجى تعداد

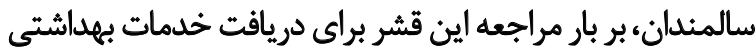

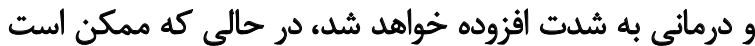

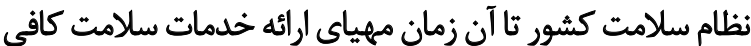

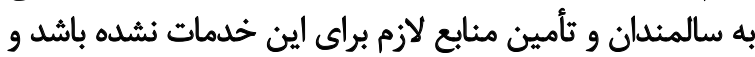

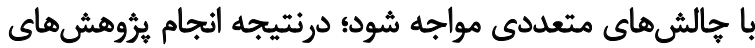

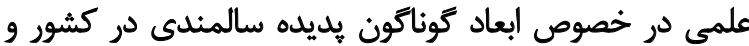

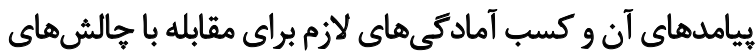

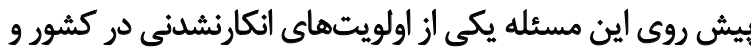

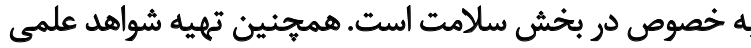

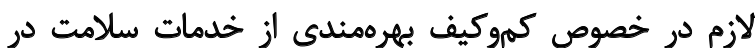

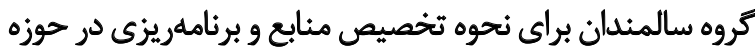

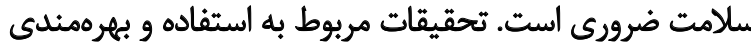

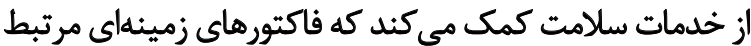

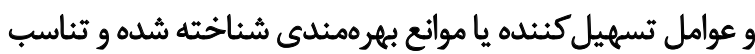
حجم و كيفيت مراقبت ارائهشده تعيين شود تا بلكه با برنامهريزي شئن 


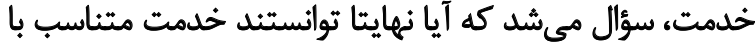

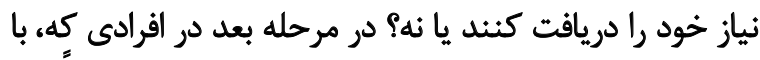

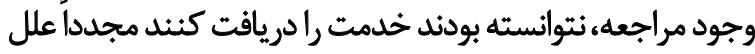

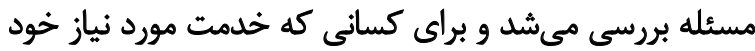

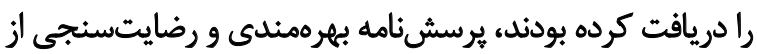

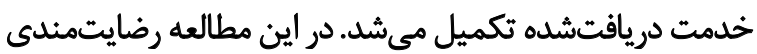

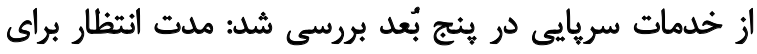

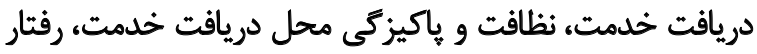

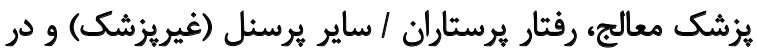

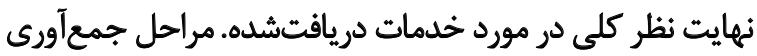

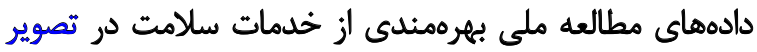
شماره ا نشان داده شده است.

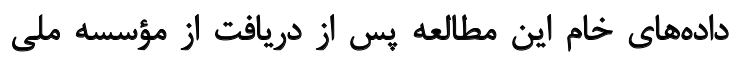

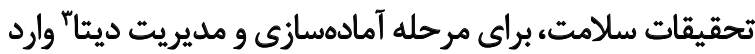

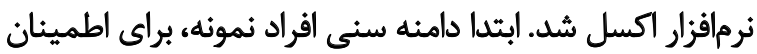

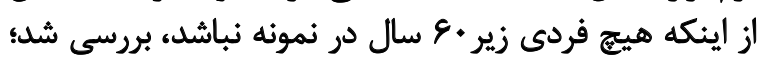

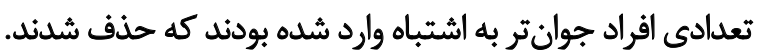

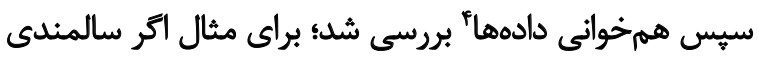

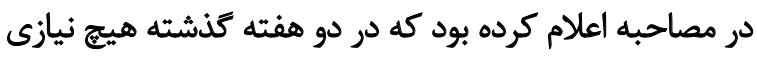

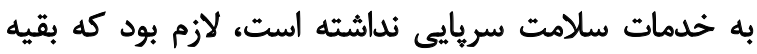

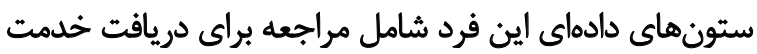

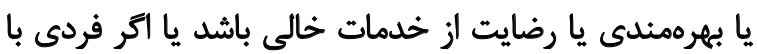

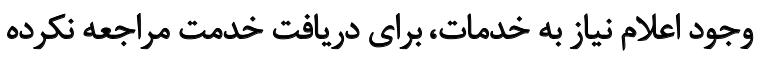

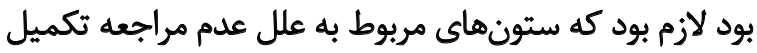

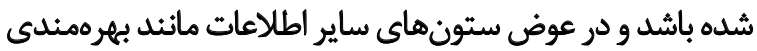

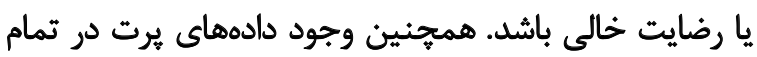

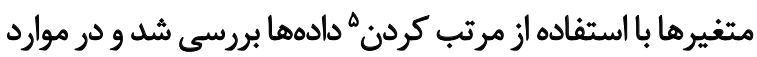

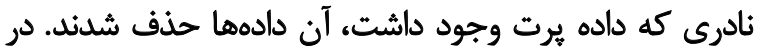

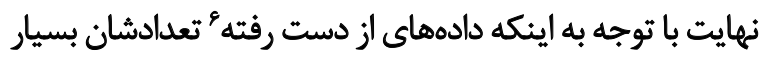

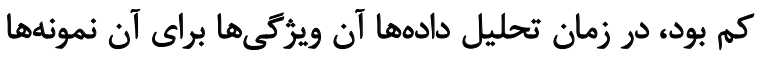

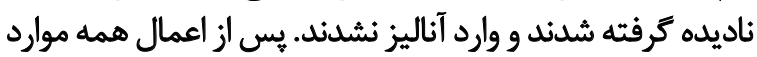

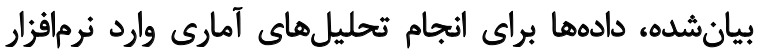
نسخه IVSSS

در اين مطالعه از آمارههاى توصيفى مانند ميانكين، فراوانى و واني

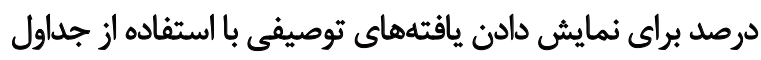

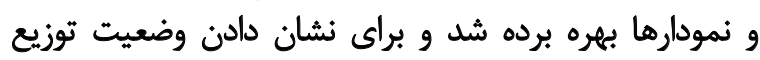

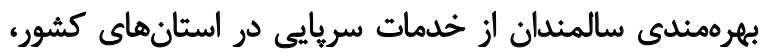

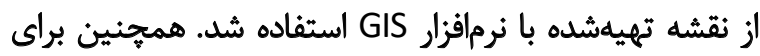

\footnotetext{
3. Data cleaning and data management

4. Consistency check

5. Sorting

6. Missing data
}

و در سطح كشور بررسى شده است. اميد است يافتههاى اين

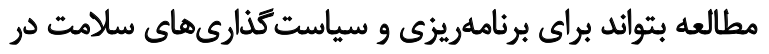

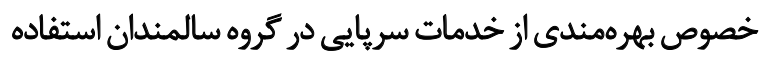

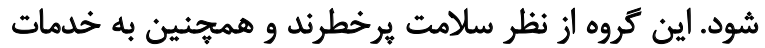

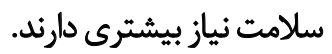

$$
\text { ووش مطالعه }
$$

برؤشش حاضر از نوع مطالعات آناليز ثانويه' است و بر اساس

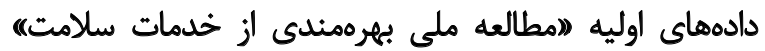

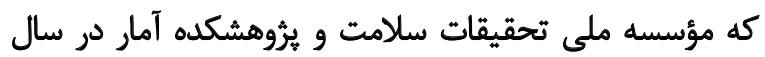

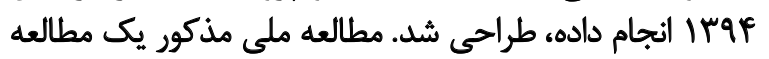

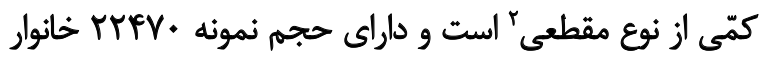

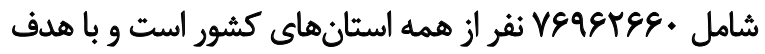

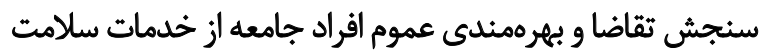

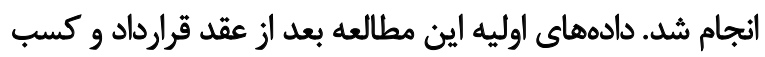

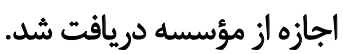

جامعه آمارى بررسىشده در مطالعه حاضر را سالمندان

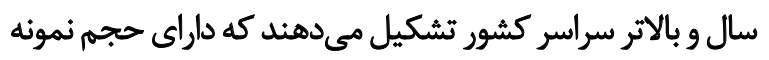

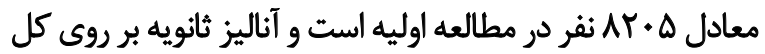

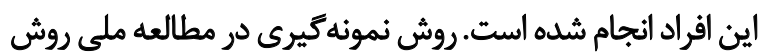

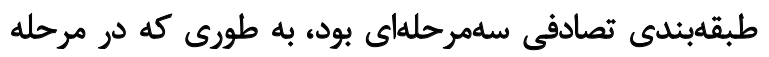

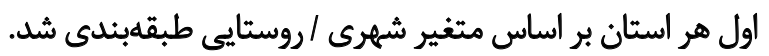

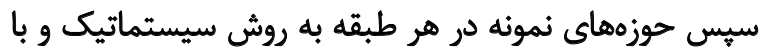

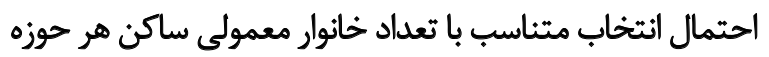

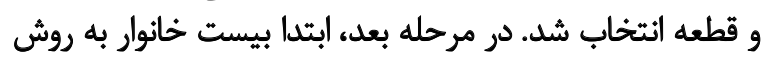

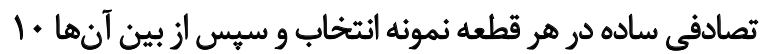

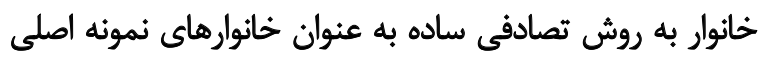

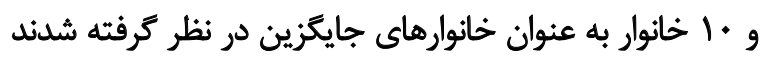

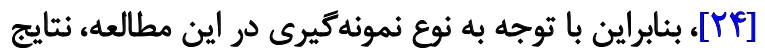
اين مطالعه قابل تعميم به كل سالمندان كشور است.

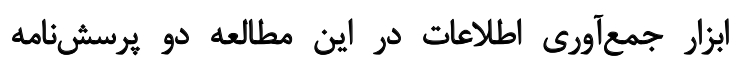

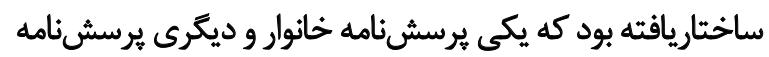

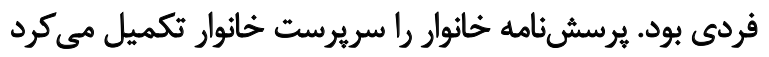

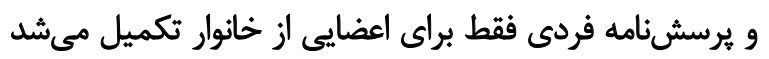

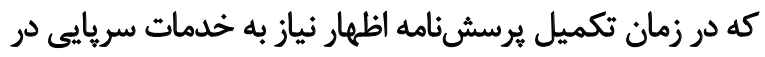

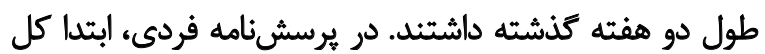

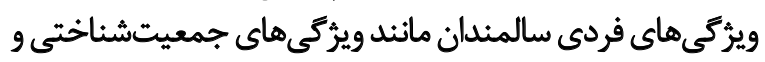

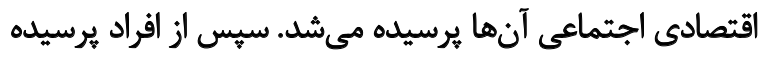

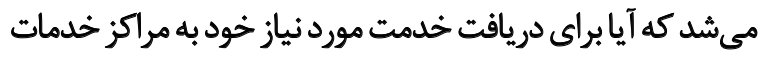

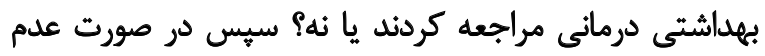

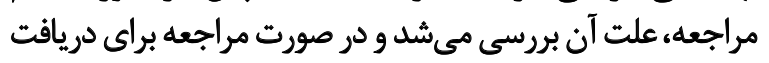

1. Secondary analysis

2. Cross-sectional 


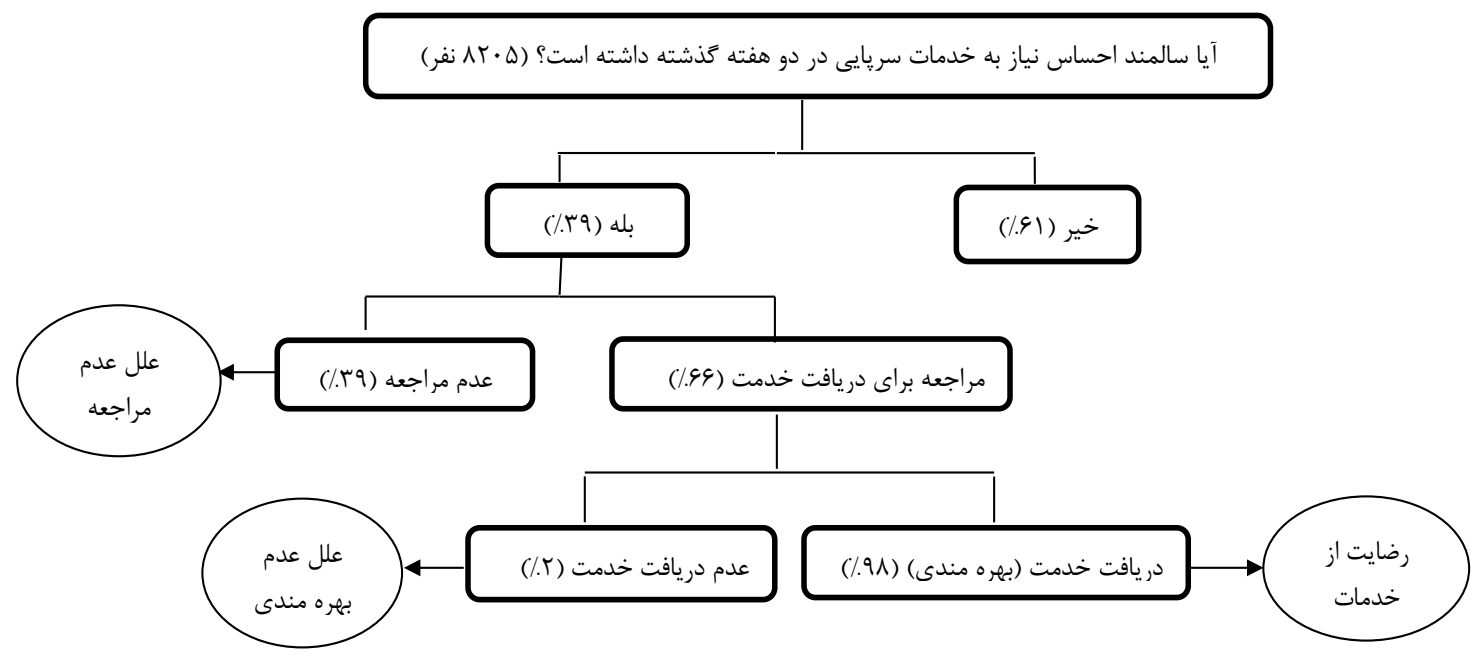

닌

تصوير ا. مراحل بررسى وضعيت بهرهمندى از خدمات سلامت سريايى در سالمندان كشور

مكمل، مالكيت مسكن، وضعيت تأهل و داشتن وسيله نقليه وارد مدلهاى ركرسيونى شدند. تمام تحليل هاى آماريت مارى با استفاده از

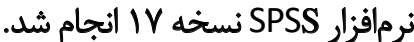

ياقتهها

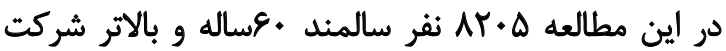

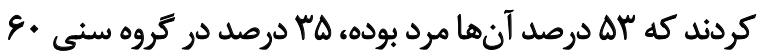

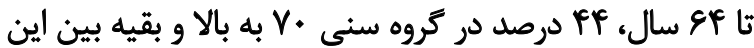

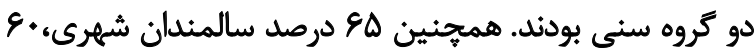

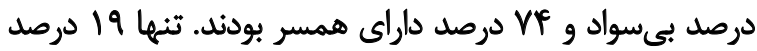

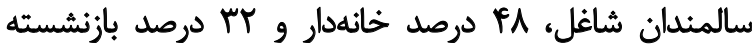

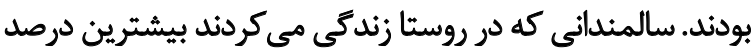

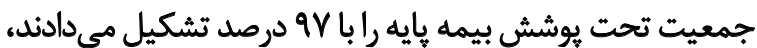

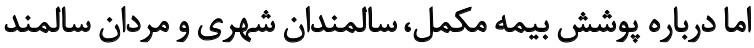

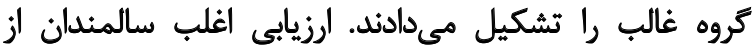

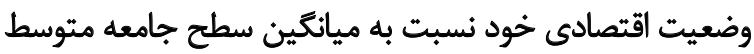

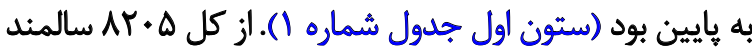
شركت كننده در اين مطالعه،

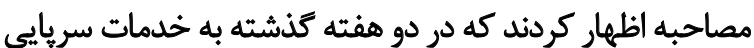

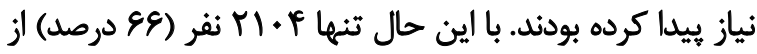

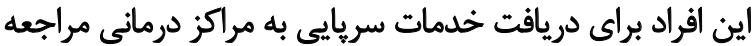

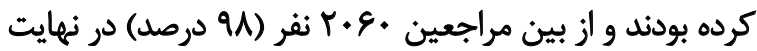

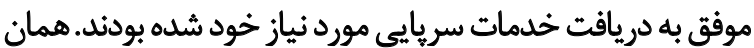

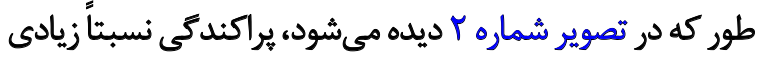

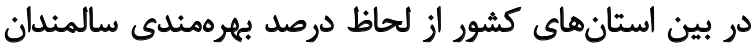

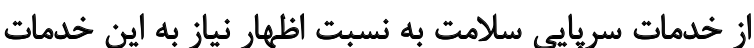

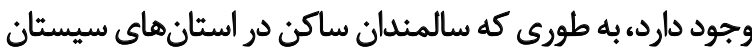

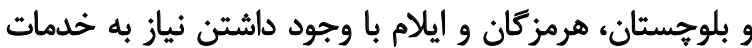

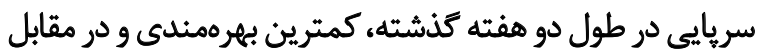

اهداف تحليلى و تعيين عوامل مرتبط با اظهار نياز به خدمات

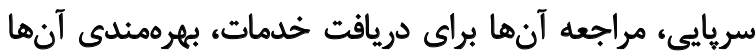

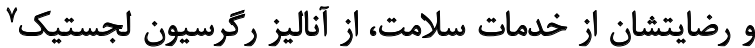

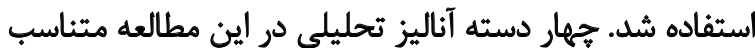

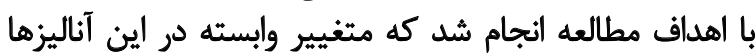

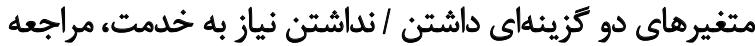

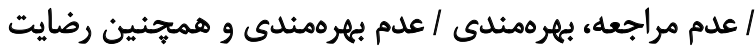

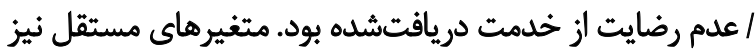

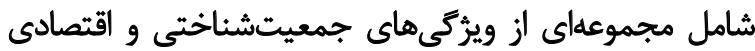

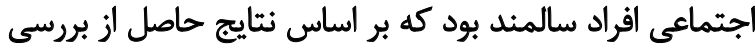

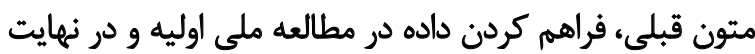

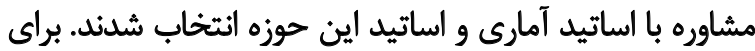

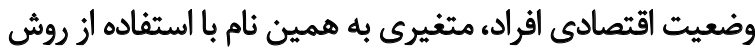

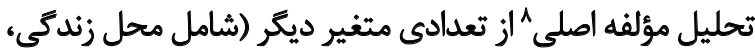

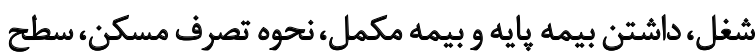

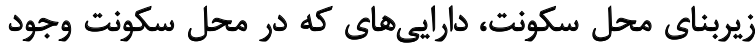
دارد، وجود اتومبيل، موتور سيكلت، رايانه، اينترنت، آشيزئن آنانه،

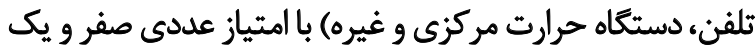

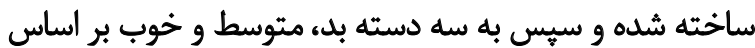

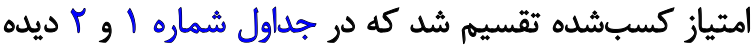

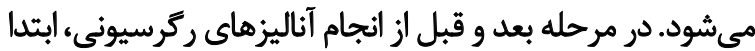

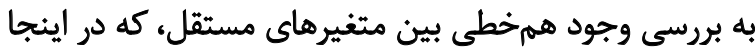

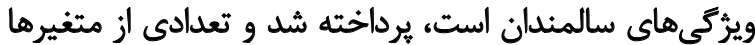

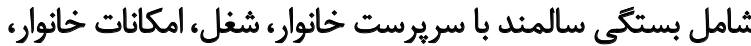

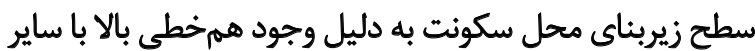

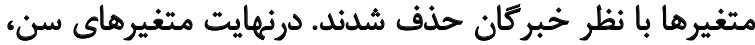

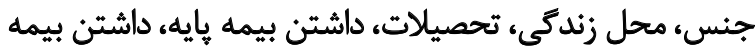

7. Logistic Regression Analysis

8. Principal Component Analysis (PCA) 


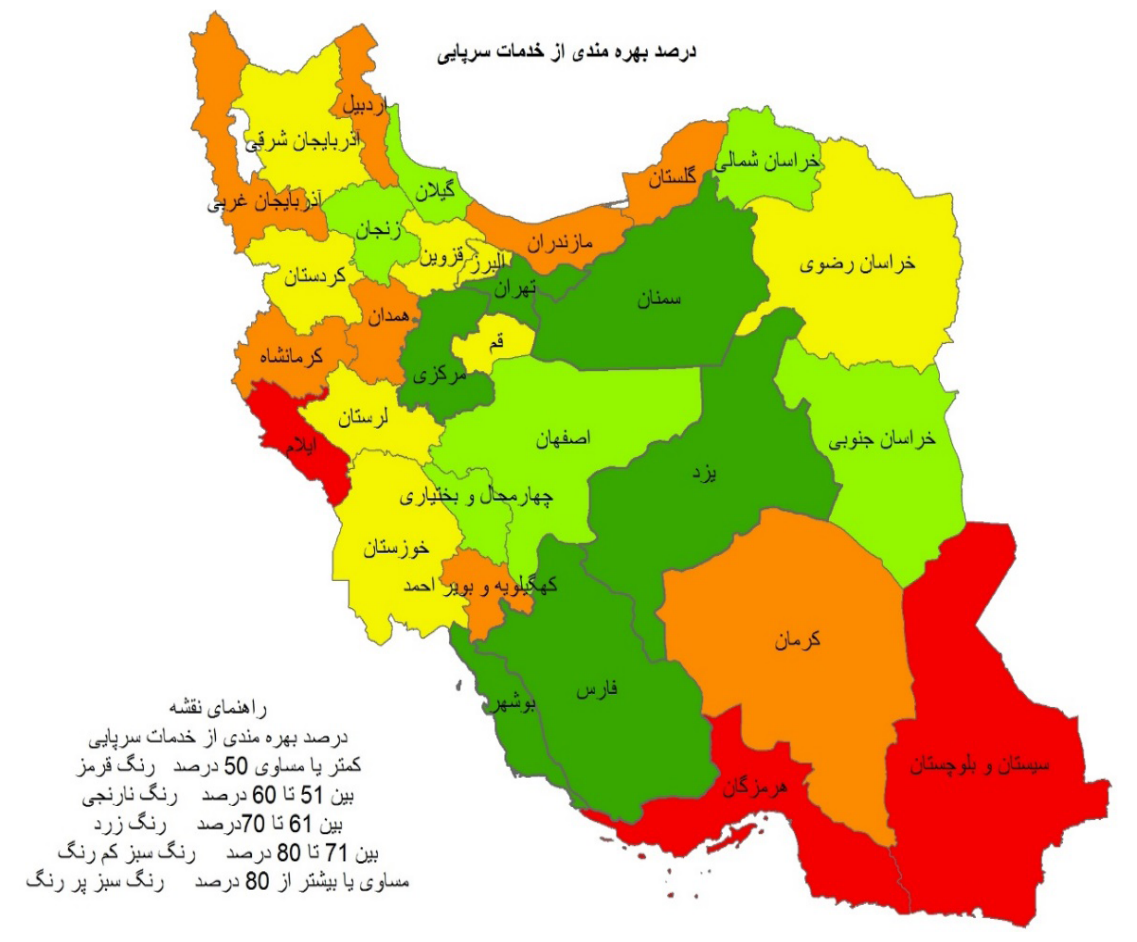

تصوير T. توزيع درصد سالمندان بهرهمندشده از خدمات سريايى سلامت به نسبت اظهار ئياز در استانهاى كشور

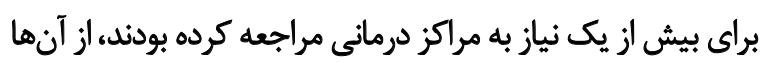

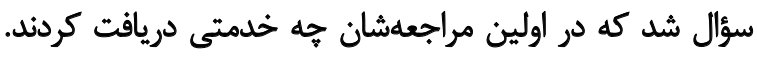

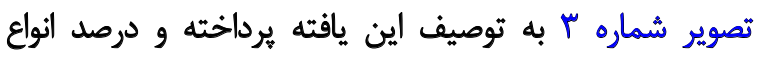

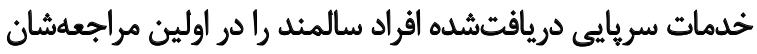

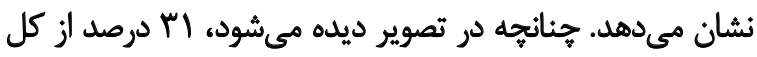

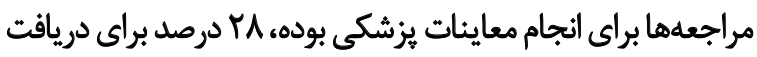

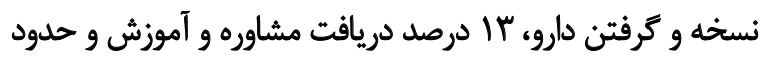

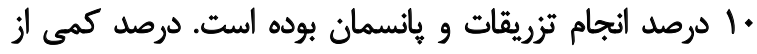

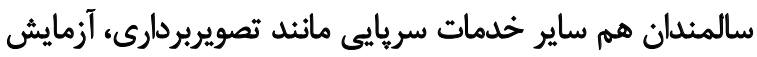

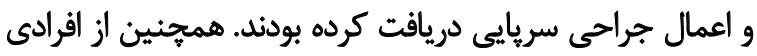

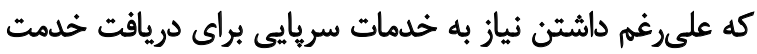

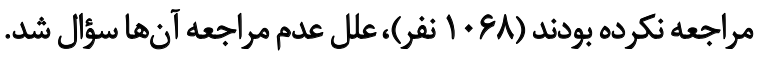

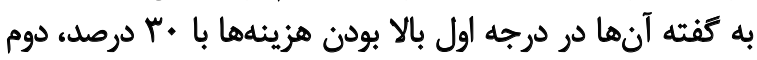

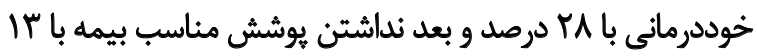

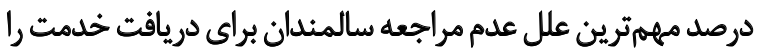

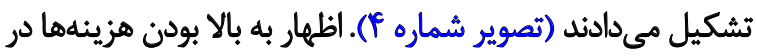

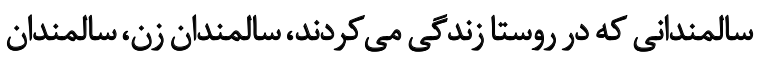
بى سواد و سالمندان بدون همسر بيشتر از سايرين بودئ

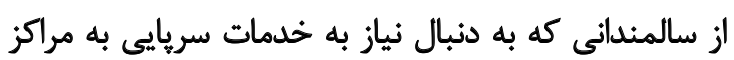

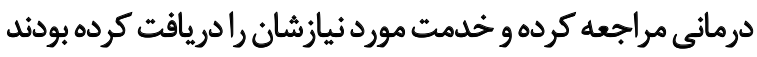

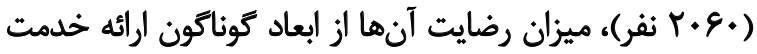

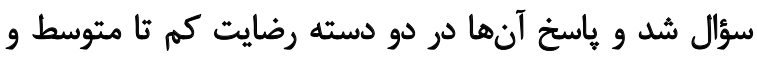

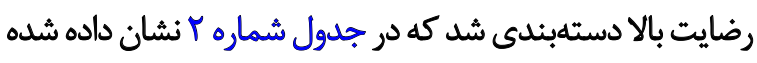

سالمندان استانهاى تهران، فارس، مركزى، يزد، سمنان و بوشهري

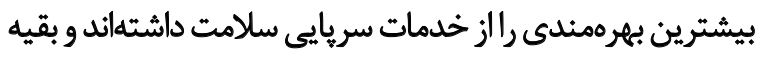
استانها در بين اين دو محدوده قرار داشتيند.

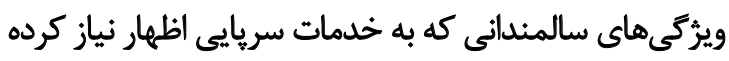

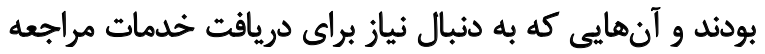

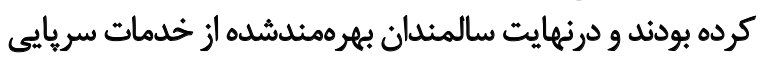

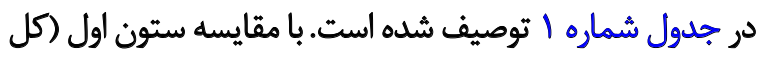

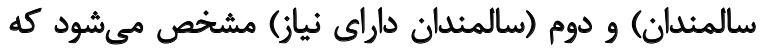

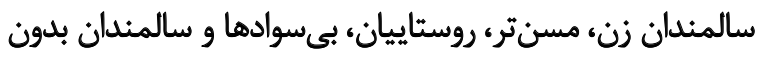

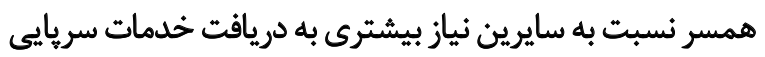

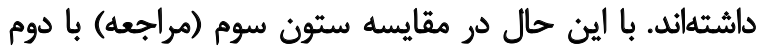

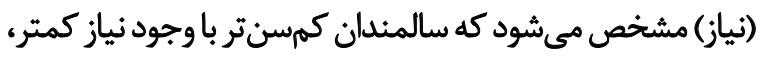

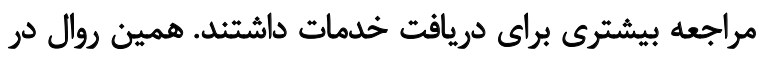

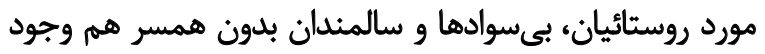

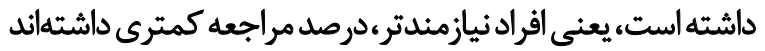

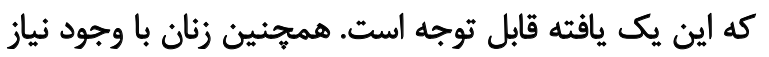

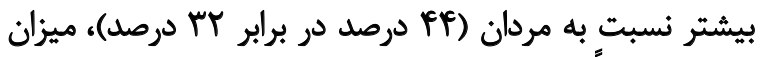

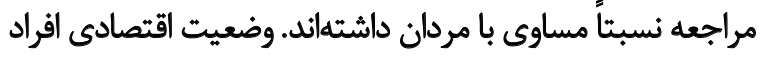

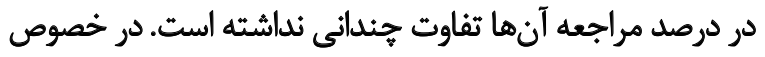

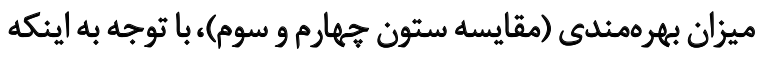

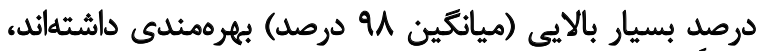

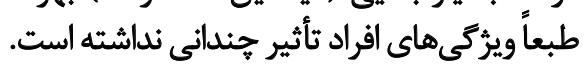
با توجه به اينكه بعضى از سالمندان در طول دو هفته كذشته 


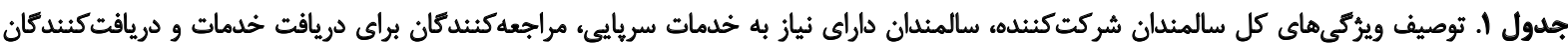
(بهرهمندشدكان) خدمات سريايى سلامت

\begin{tabular}{|c|c|c|c|c|c|}
\hline \multicolumn{4}{|c|}{ تعداد (دوصد) } & \multirow[b]{2}{*}{ ويرّكى هاى سالمندان } & \multirow[b]{2}{*}{ مثغيرها } \\
\hline دريافت كنندكان خُمتب، & دريافت خدمثت (به دئدان براي & أفرادي كه نياز به & كل افراد نمونه & & \\
\hline १พจ (9ท/9) & $9 \Delta 9(8 \Delta / A)$ & lfas $(\pi T / K)$ & $\operatorname{prne}(\Delta t / T)$ & هرد & \multirow{2}{*}{ 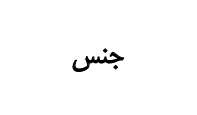 } \\
\hline $11 \%$ (9V/9) & llid (Eg/V) & IVIS (riv) & PATI (FEM) & زن & \\
\hline$e q / r^{r}$ & $e q / \varphi$ & $e q / 1 / 1$ & equ & ميانكين سن & \multirow{4}{*}{ سن } \\
\hline$V \cdot \Delta(9 V / q)$ & $V \cdot(\varepsilon q / T)$ & $1.49(r \Delta / \Delta)$ & rarf (rه/8) & et-8. & \\
\hline FIf (WN) & $419(9 \mathrm{~V} / \cdot)$ & ETD (TV/*) & $1819(T \cdot 18)$ & $99-80$ & \\
\hline 9F) (9V/D) & $\vartheta \Delta(8 \pi / 9)$ & $10 \cdot \lambda(F 1 / 9)$ & TAQT $(R T / A)$ & V به بالا V. & \\
\hline$|r q|(q Y / A)$ & $11919(8 g / A)$ & $19 V^{\prime}(T \& / A)$ & $\Delta r \Delta \cdot(\varepsilon \Delta / Y)$ & شهي & \multirow{2}{*}{ همل زند5ى } \\
\hline VEA (qV/q) & $\operatorname{rA\Delta }(\rho \Delta / \%)$ & $1199(7) / 9)$ & $r A \Delta \Delta(M F / A)$ & 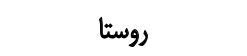 & \\
\hline Ifex (9V/V) & Ifeq $(E V / \Delta)$ & MMIA (MEI) & $\sin (n+A)$ & متأهل & \multirow{2}{*}{ وضعيت تأهل } \\
\hline$\Delta q \varepsilon\left(W W^{\prime}\right)$ & $8 \cdot 8(9 / \Delta)$ & $9 \Delta F(F \& / 1)$ & $r+\& A(T \Delta / T)$ & غيرمتأهل & \\
\hline$W F(W V)$ & $V M E(V / q)$ & $1.94(r T / T)$ & $\operatorname{MTAS}(t+1 \%)$ & با سواد & \multirow{2}{*}{ تحصيلات } \\
\hline $\operatorname{IYAP}(9 \vee / F)$ & $\operatorname{IM} M\left(\mathscr{R} / T^{\prime}\right)$ & $Y \cdot A \cdot(T T / T)$ & $p q r \cdot(\varepsilon \cdot 1 \cdot)$ & إيىسواد & \\
\hline ทั\& (99/.) & $\operatorname{ner}(M / \Delta)$ & $1 . r A(f \circ / 9)$ & rATV $(T \cdot / 9)$ & 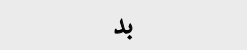 & \multirow{5}{*}{ *" وضعيت اقتصادى } \\
\hline$V \cdot Y(9 V / V)$ & $n q(E q / \Delta)$ & $1 \cdot m p(f \cdot / 8)$ & TAPE $(\mathrm{MV} / \cdot)$ & متوبط & \\
\hline $\operatorname{sir}(9 V /)$ & $e r \cdot(\varepsilon \cdot / \pi)$ & $1 .+4(f+/ 9)$ & raFA $(M M /)$ & 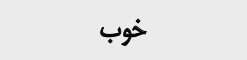 & \\
\hline$\wedge$ & ir & $\Delta \varphi$ & $\Delta V=(V / *)$ & علم ياسيخ & \\
\hline$r+q+(q V / q)$ & $M / H(\Phi g / M)$ & MIVT (TNE) & $\Delta r \cdot \Delta(1+\circ / \cdot)$ & كل سالمثدان & \\
\hline
\end{tabular}

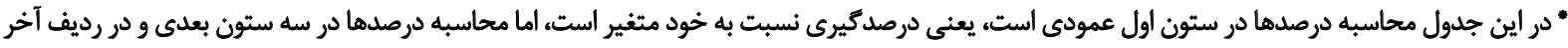

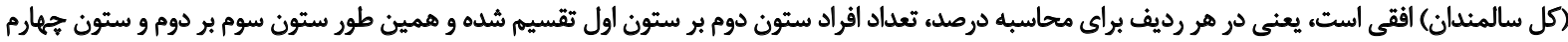

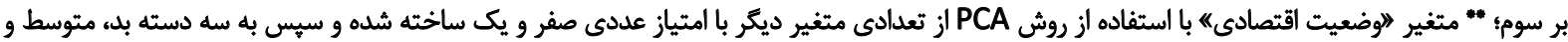

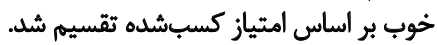

اينكه مسن ترها، بيىسوداها و نيز ثروتمندان نسبتاً ناراضيتر بودند.

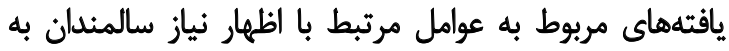

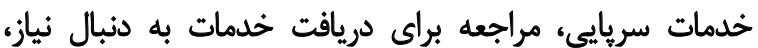

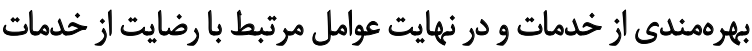

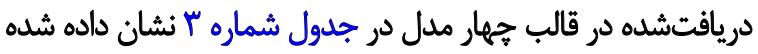

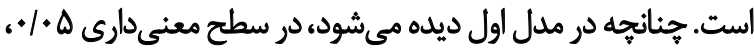

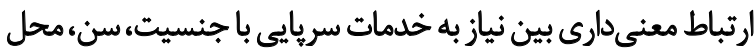

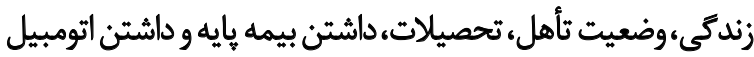

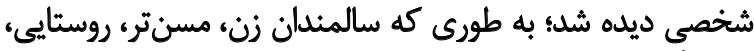

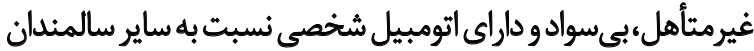
اطهار نياز بيشترى به خدمات سريايى داشتئل و سالمندان فاقد بيمه يايه، نسبت به كساني كه بيمه داشتئد، اظهار نياز كمترى به به خدمات
ست. ميزان رضايت كلى هf در صد از دريافت كنيدكان خدمت در

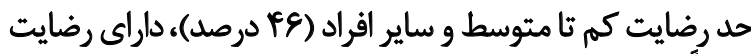

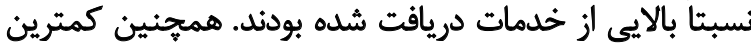

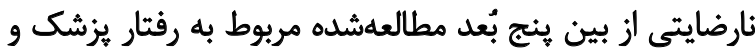

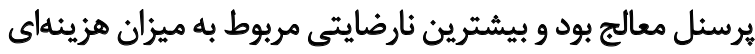

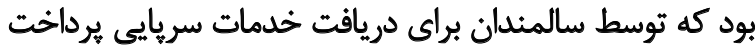
مىشد. از نظر نظافت و واكيزگ

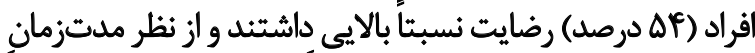

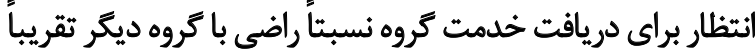

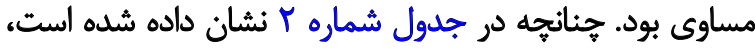

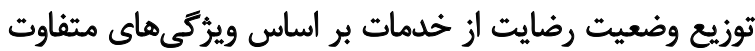

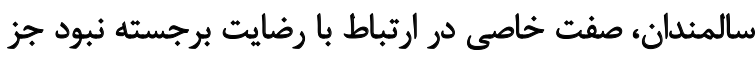




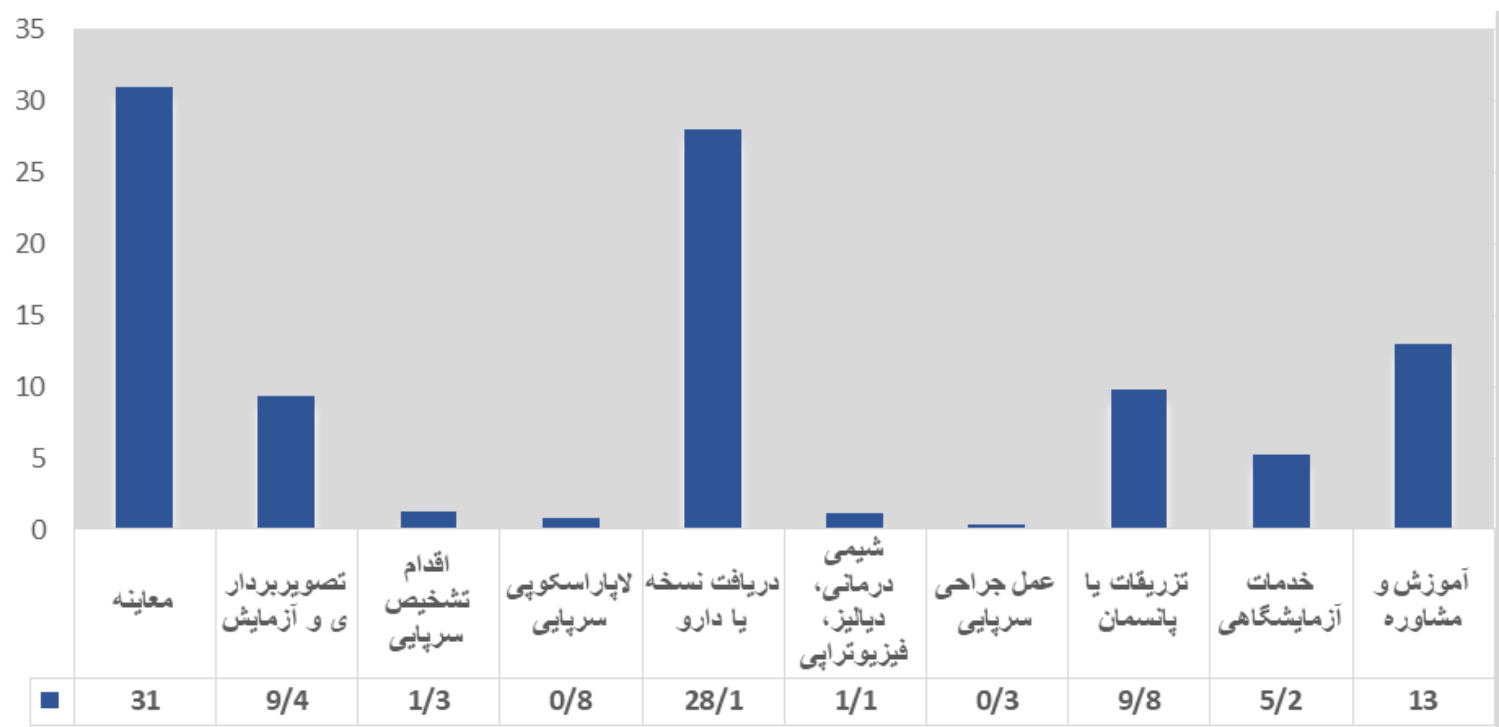

تصوير ب. درصد انواع خدمات سريايي دريافتشده توسط افراد سالمثد براي اولين نيازشان در طول دو هفته مكُشته

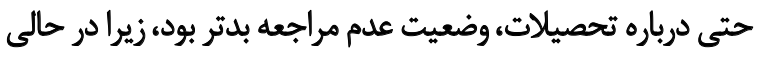

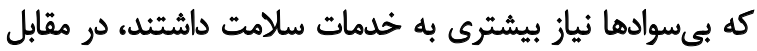

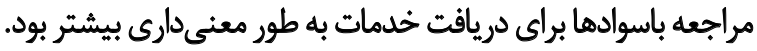

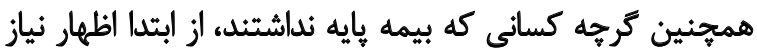

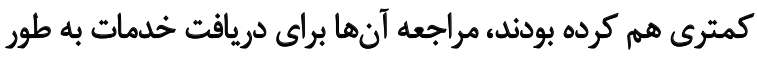

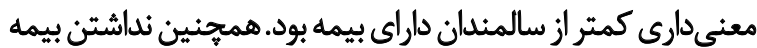

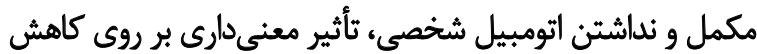

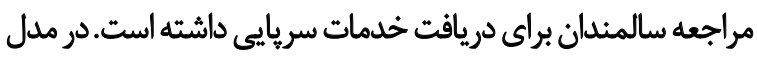

داشتند. جنانجه ديده مىشود، رابطهاي بين نياز سالمندان به خدمات

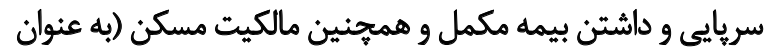

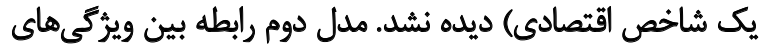

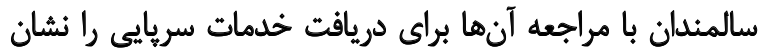

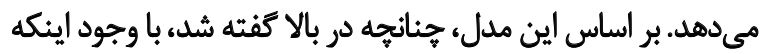

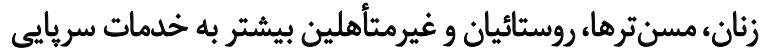

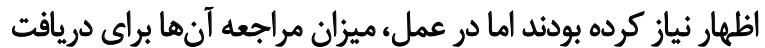

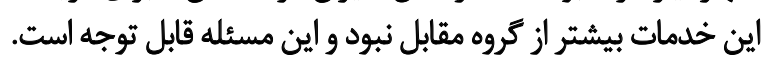

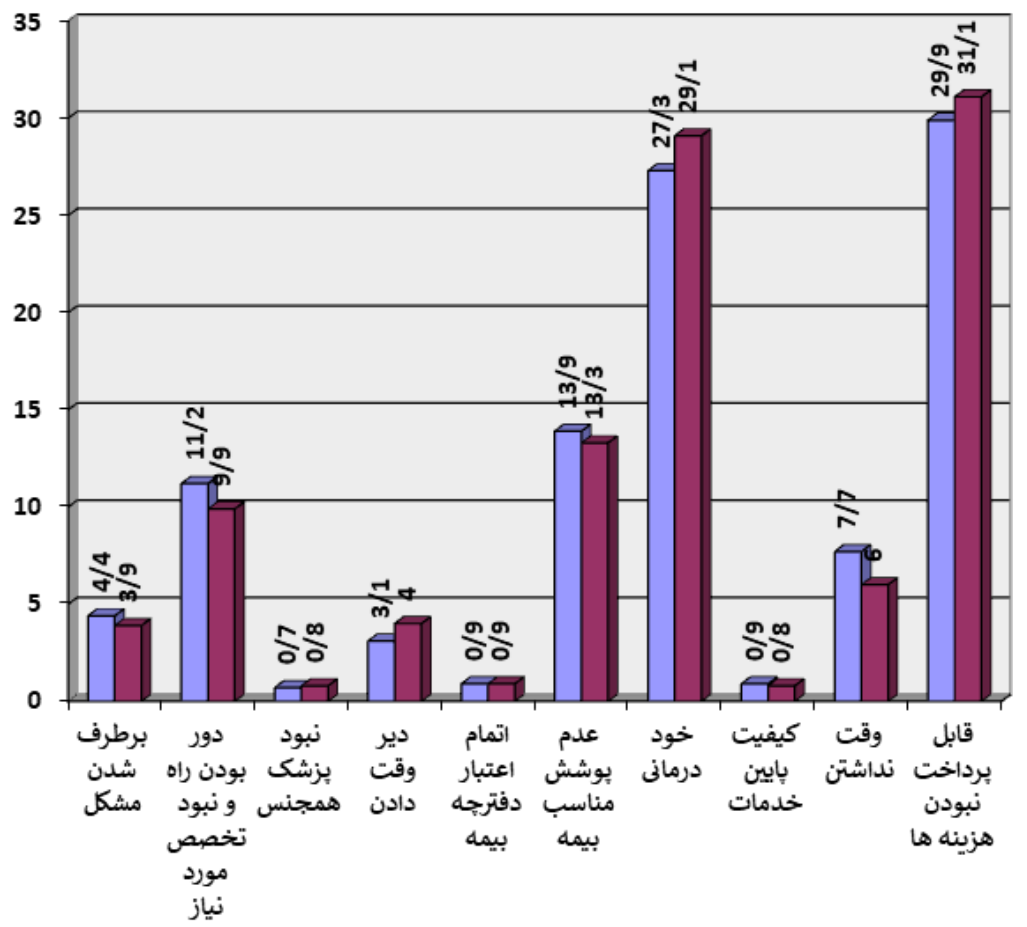


جدول r. وضعيت رضايت سالمندان از ابعاد كونائون خدمات سريايى دريافتشده به تفكيك ويزّكىهاى آنها

\begin{tabular}{|c|c|c|c|c|c|c|c|c|c|c|c|}
\hline & ركلى رايت & تش تشده & هزينه يور & و يرسينل & رفتار يزش & يزئكي & نظافت و مر & لدمت & مدت أثثة & \multirow{3}{*}{\multicolumn{2}{|c|}{ ويزوكى هاى سالمندان }} \\
\hline \multicolumn{10}{|c|}{ درصد } & & \\
\hline خوب & ضتويف ثا & خوب & ضتوسيف ثان & خوب & ضتوسيف ثنا & خوب & ضتوسيف ثا & خوب & ضتويف تا & & \\
\hline$e f / r$ & $\Delta \Delta / T^{\prime}$ & $r v$ & $\mathrm{eq}$. & $\Delta \% / 0$ & $P r / \Delta$ & $\Delta M \%$ & evl. & PNY & D1/8 & هرد & \multirow{2}{*}{$\xi$} \\
\hline $\mathrm{PV} /$. & $\Delta M /$ & $\pi \%$ & \&\&l. & $\Delta V / \&$ & $r T / F$ & $\Delta \Delta / \Delta$ & $H F / Q$ & $\Delta V / *$ & $\mathrm{rq}$. & زن & \\
\hline$p e / q$ & $\Delta r / 1$ & $r \Delta /$. & $8 \Delta /$. & 8.1 & $p \circ$ & $\Delta V /$. & $\mathrm{mm} /$ & $\Delta T /$. & PN. & $8 \Delta-8$. & \multirow{3}{*}{$\xi_{\xi}$} \\
\hline $\mathrm{Pal} / \mathrm{.}$ & $\Delta Q /$. & $\pi / F$ & 8918 & $\Delta N$ & $\mathrm{Prl}$ & $\Delta \Delta / V$ & $\mu p / \mu$ & $\Delta \cdot / \Gamma$ & pqu & $V \cdot-80$ & \\
\hline$P a / \Delta$ & $\Delta f / \Delta$ & $M /$ & \&VP. & Def/ & $r \Delta / f^{e}$ & $\Delta 1 / f^{e}$ & INF & $e v / f^{e}$ & AYP & و به بالا V. & \\
\hline pris & $\Delta \Delta / \digamma$ & $\pi / \Delta$ & $\notin 810$ & $i v / r$ & Ar/ & $\Delta \varphi / \Delta$ & $r \Delta / \Delta$ & PN. & arp. & شهر & \multirow{2}{*}{ है ह } \\
\hline fq/8 & $\Delta H / F$ & $m \%$ & sql. & $\Delta V / /$ & $r r / 9$ & $\Delta F /$ & $|r|$ & $\Delta T / Y$ & $P V / N$ & ل روستا & \\
\hline$p \& 1$. & $\Delta F /$ & $m \%$ & eql. & QNY & $P V / A$ & AP/E & $r \Delta /{ }^{\circ}$ & $\Delta . /$ & $\Delta .1$ & مثتاهل & \multirow{2}{*}{$\xi_{i}$} \\
\hline $\mid+91$. & $\Delta F /$ & Hr\% & $\mathrm{sVl}$. & $\Delta F / \&$ & $r \Delta / F$ & $\Delta H /$ & $|r q|$ & $\Delta+1$ & $\Delta .1$ & غيرمتأهل & \\
\hline$\Delta 1 / \%$ & PNE & $\varphi *$ & 8.1 & ST/ & $m / r$ & $\varepsilon \cdot / p$ & rage & $\Delta r / V$ & $p e / r$ & باسواد & 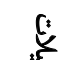 \\
\hline $\mathrm{Fr} /$ & $\Delta \mathrm{V} /$. & $\mathrm{HV}$ & sq. & $\Delta F /$ & $\mid+81$. & a) $/$. & $\mathrm{rq} / \mathrm{.}$ & YN. & $\Delta r /$ & بكىسواد & $y_{z}$ \\
\hline$\Delta 1 / 1$ & PNA & $\mathrm{ra/p}$ & $9 \cdot / \pi$ & $\mathrm{gr/}$ & rN. & $\Delta Q / \Delta$ & $P \cdot 10$ & $\Delta r / q$ & PVI & بد & \\
\hline PV/A & $\Delta r / T$ & $\pi / \Lambda$ & $\operatorname{sedr}$ & $\Delta N A$ & rir & $\Delta S / M$ & $m / V$ & $\Delta r / *$ & FN. & متوسط & \\
\hline \multirow[t]{3}{*}{$e v / 0$} & $\Delta N \Delta$ & $r \cdot / \Delta$ & $E q / \Delta$ & $\Delta Y / F$ & $P V / P$ & $p q / f$ & 0.18 & $P V / r$ & $\Delta T / V$ & خوب & 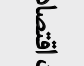 \\
\hline & - & - & - & - & - & - & - & - & - & علم باسخ & 6 \\
\hline & $\Delta F=$ & $\pi / N$ & $\operatorname{sedr}$ & $\Delta V / 1$ & Rr/q & $\Delta f / f$ & PA/ & $p q / \Lambda$ & $\Delta . / r$ & كل سالمنان & \\
\hline
\end{tabular}

C

ثُ

در اين مطالعه وضعيت نياز، تقاضا و بهرهمندى از خدمات

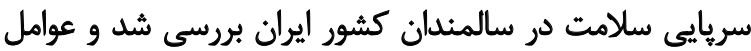

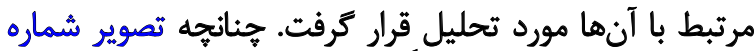

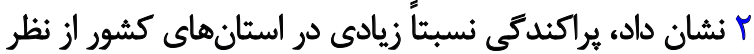

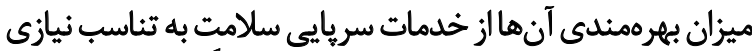

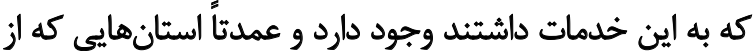

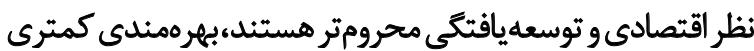

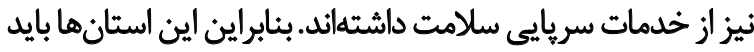

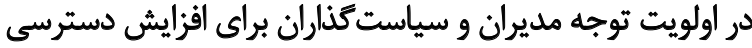
عادلانه آنها به خدمات سلامت مورد نيازنشان قرار كيرند.

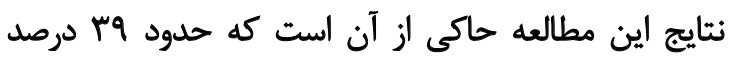

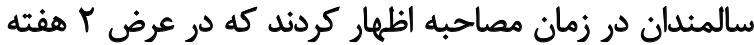

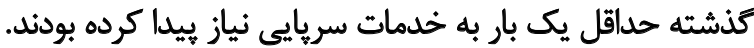

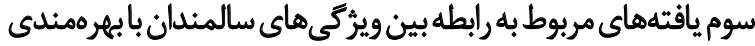

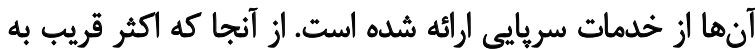

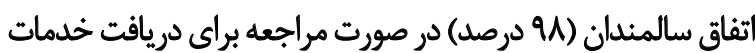

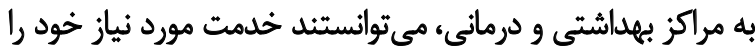

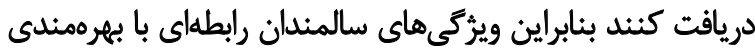

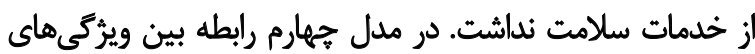

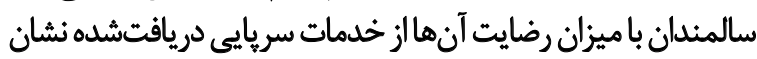

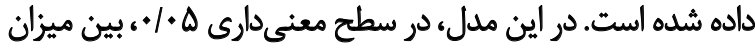

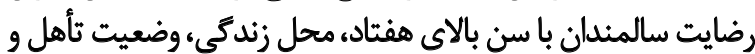

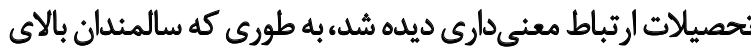

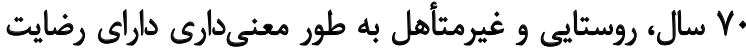

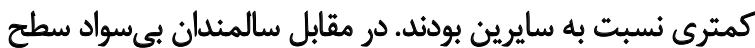

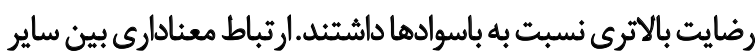
ويرُكى ها و رضايت از خدمات ديده نشد. 
جدول ب. نتايج آناليز ركرسيون لاجستيك براى تعيين عوامل مرتبط با اظهار نياز سالمندان، مراجعه آنها به دنبال نياز، بهرهمندى آنان به دنبال مراجعه و رضايت

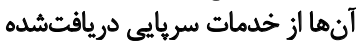

\begin{tabular}{|c|c|c|c|c|c|c|c|}
\hline \multicolumn{2}{|c|}{ مدل ع. رضايت داشتن } & \multicolumn{2}{|c|}{ مدل ". بهرهمند شدن } & \multicolumn{2}{|c|}{ مدل ז. مراجعه كردن } & \multicolumn{2}{|c|}{ مدل (. نياز داشتن } \\
\hline OR (৭४\% Cl) & $\mathbf{P}$ & OR (१ه\% Cl) & $\mathbf{P}$ & OR (৭৯\% Cl) & $\mathbf{P}$ & OR (৭৯\% Cl) & $\mathbf{P}$ \\
\hline
\end{tabular}

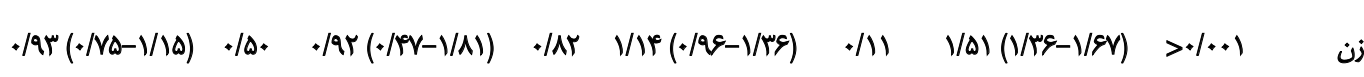

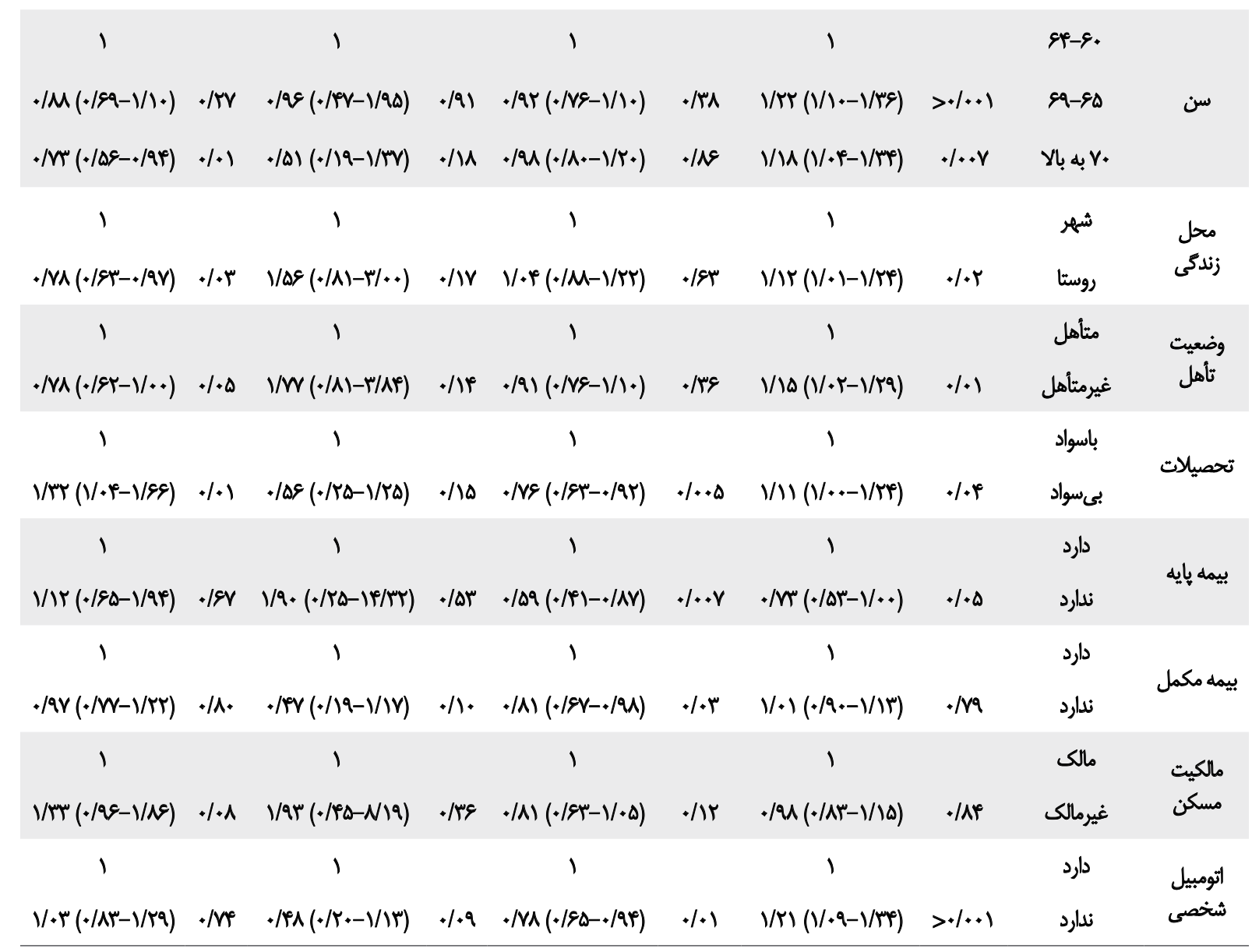

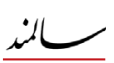

تعيين سلامت سالمندان و نيازهاي سلامتى آنان انجام معاينات

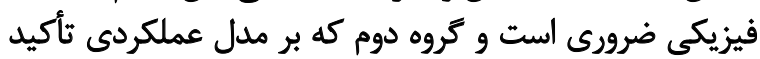

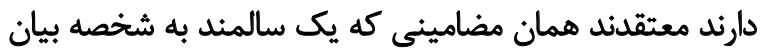

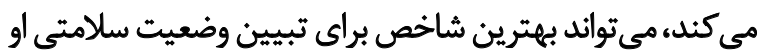

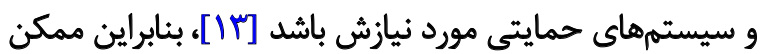

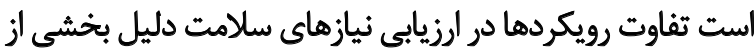

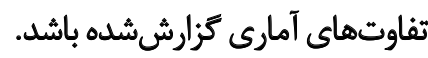

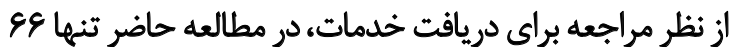

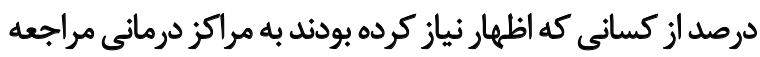

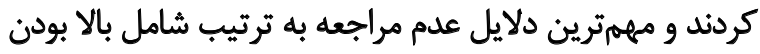

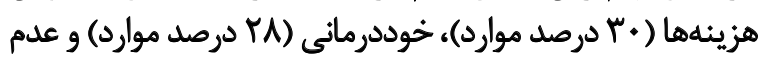

اين مقدار در مقايسه با نتايج مطالعه ماديانين كروم و همكاران

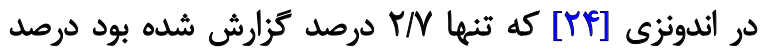

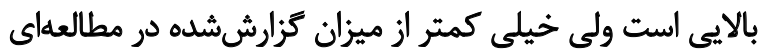

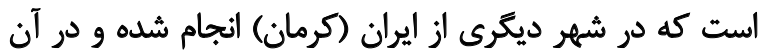

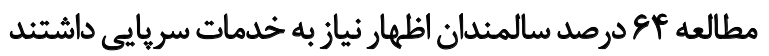

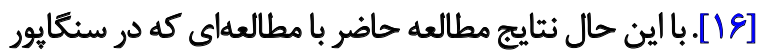

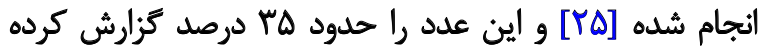

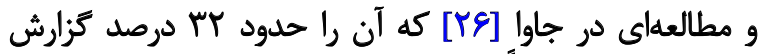

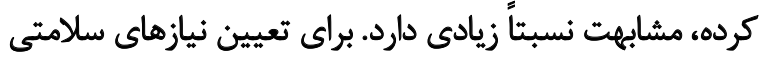

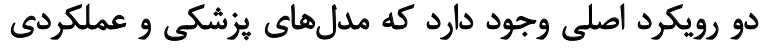

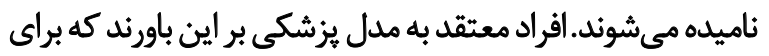


در تايوان و هارك در كره، زنان سالمند نسبت به مردان ميزان

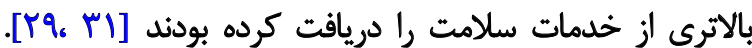

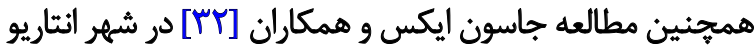

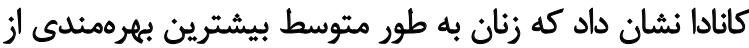

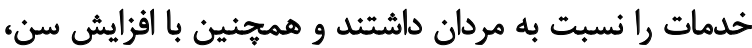

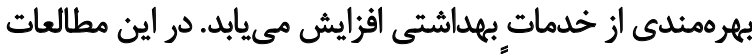

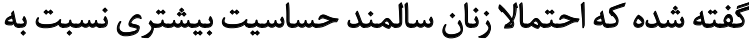

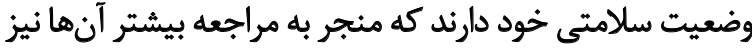

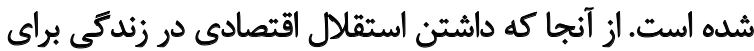

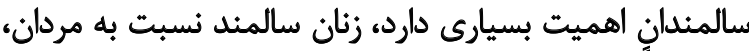

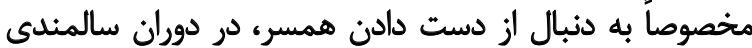

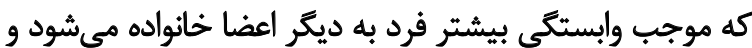

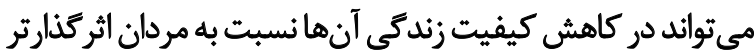

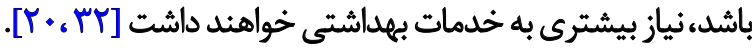

انتظار مىرود كه مسنترها به خدمات سلامت نياز بيشترى

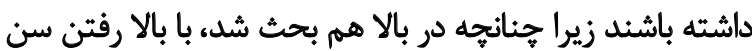

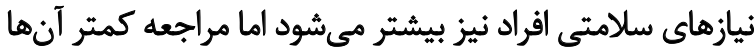

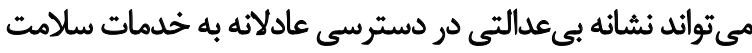

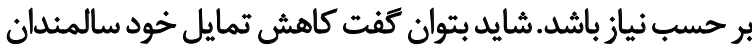

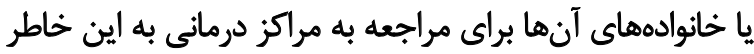

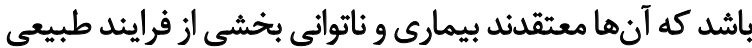

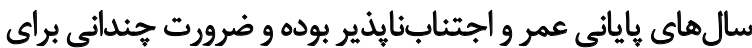

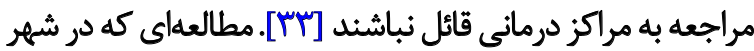

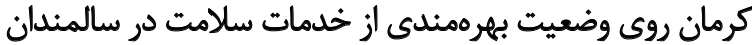

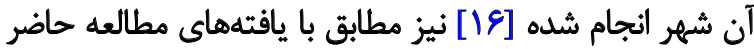

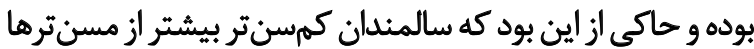

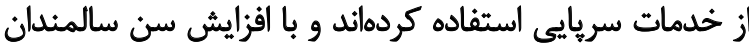

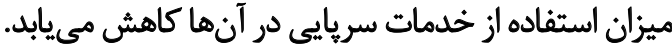

همجنين سالمنداني كه در روستا زندكى مى كردند اظهيار نياز

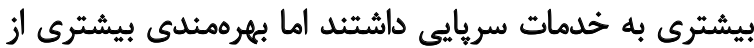

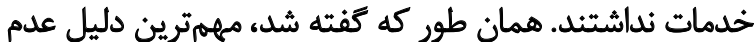

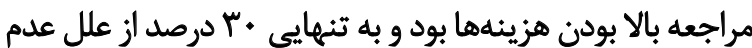

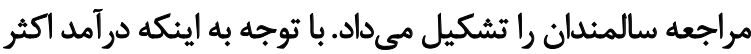

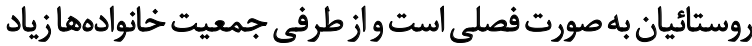

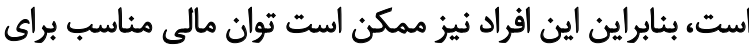

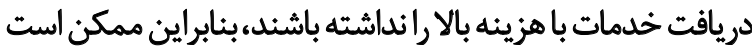

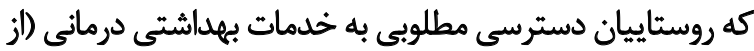

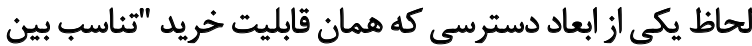

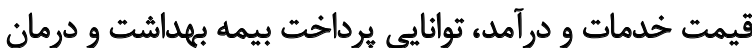

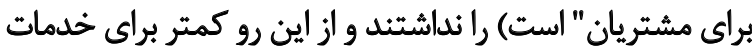

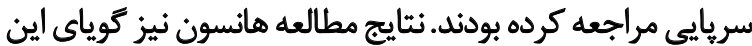

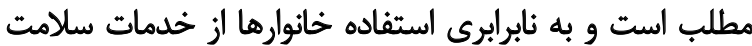

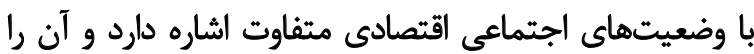

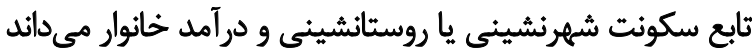

يوشش مناسب بيمهاي (rائ درصد موارد) ذكر شده بود. عدم

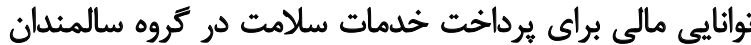

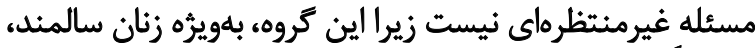

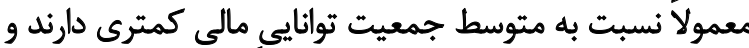

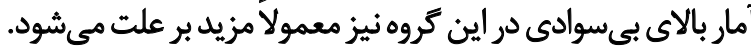

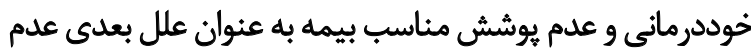

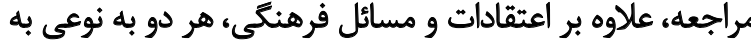

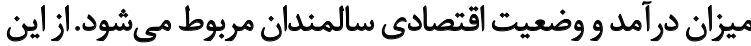

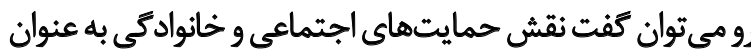

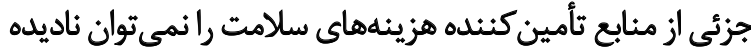

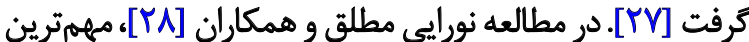

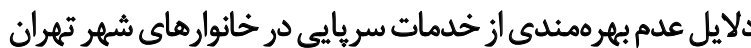

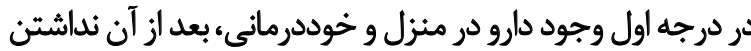

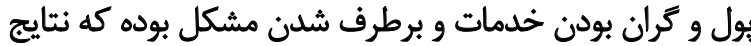

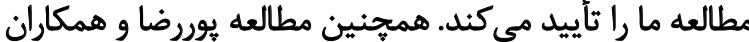

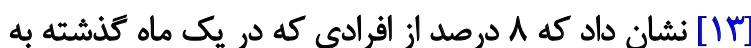

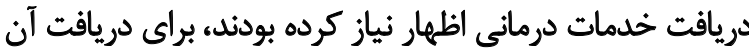

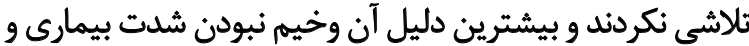

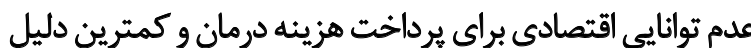

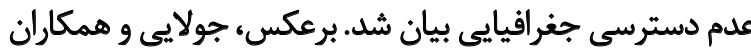

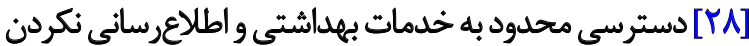

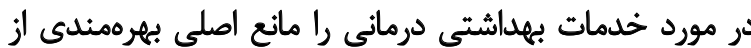

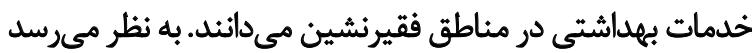

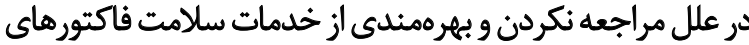

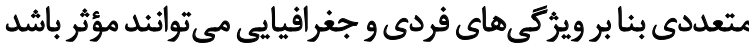

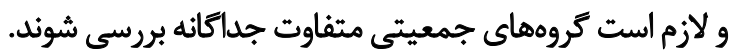

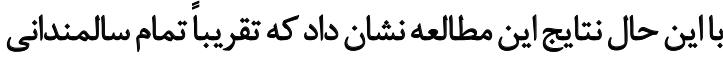

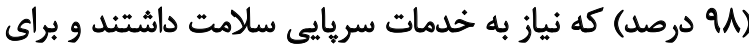

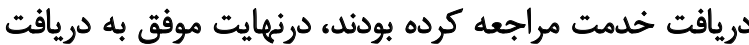

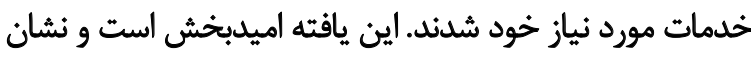

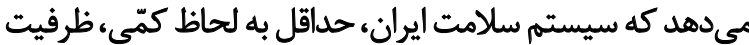
ارائه خدمات سريايى مناسبى به مراجعين داردا در تحليل عوامل مرتبط با نياز و مراجعه براى دريافت

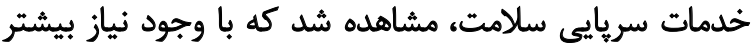

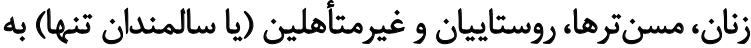

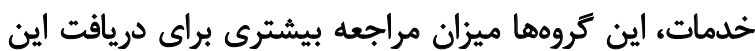

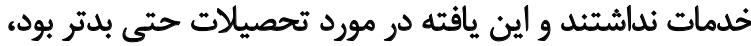

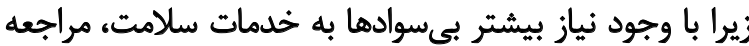

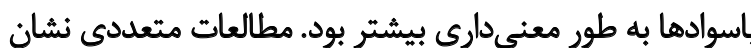

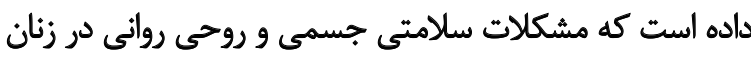

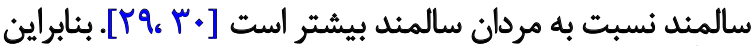

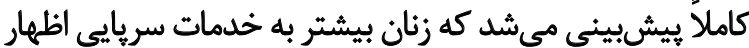

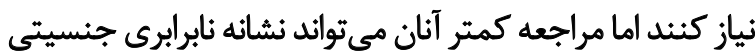
در دسترسى برابر به خدمات سلامت باشد. در مطالعات هانئك 


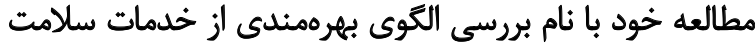

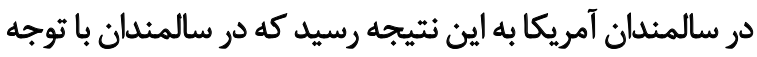

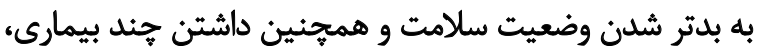

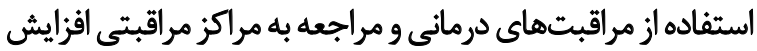

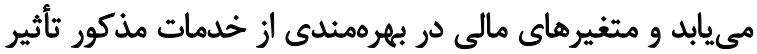

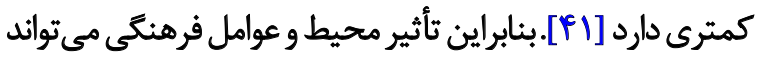

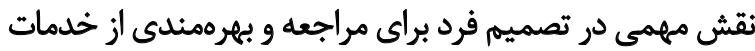
سلامت داشته باشد.

در خصوص رضايت از خدمات سريايى مطالعه حاضر نشان داد

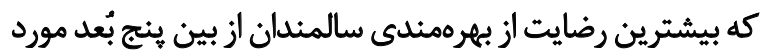

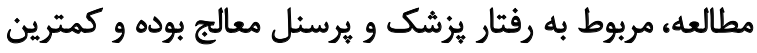

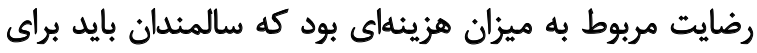

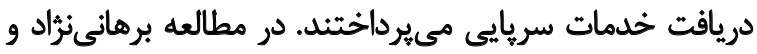

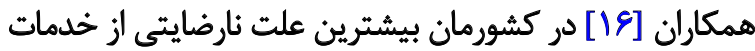

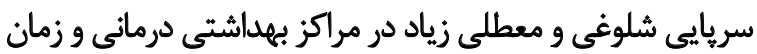

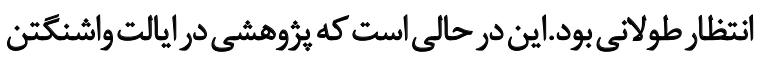

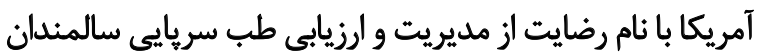

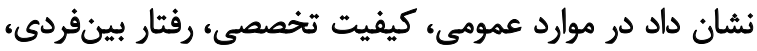

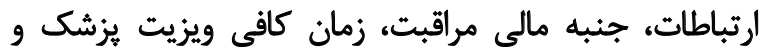

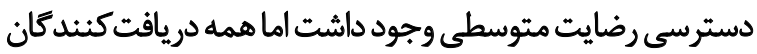

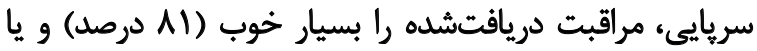

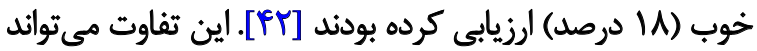

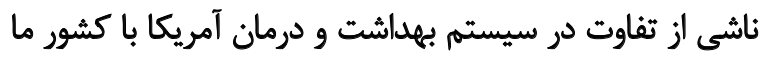

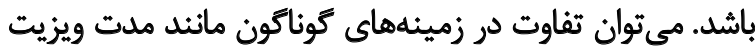

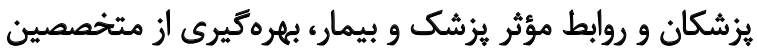

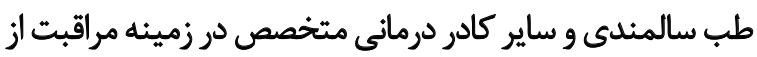

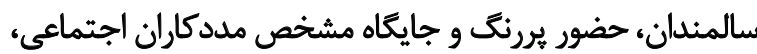

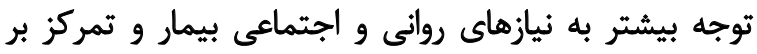

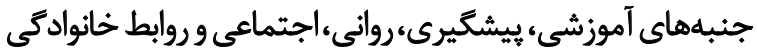

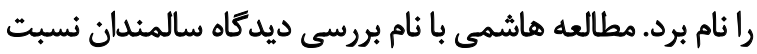

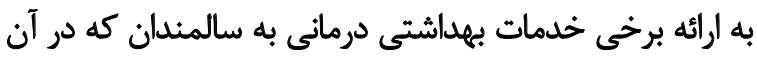

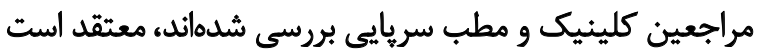

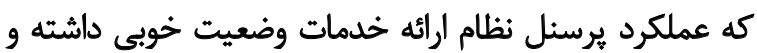

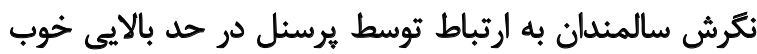

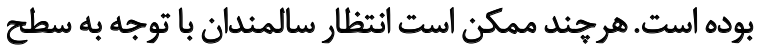

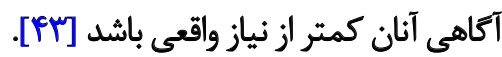

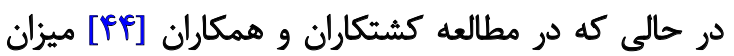

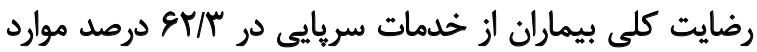

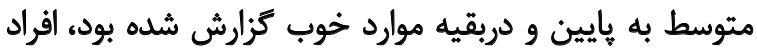

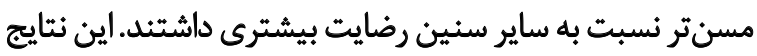

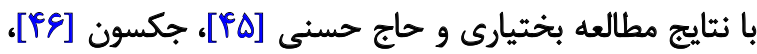

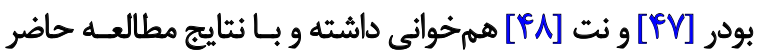

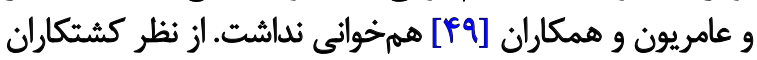

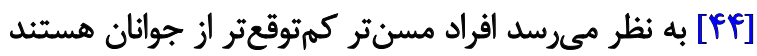

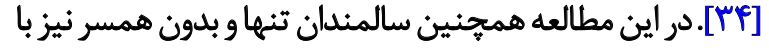

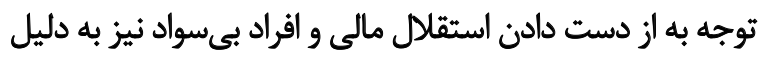

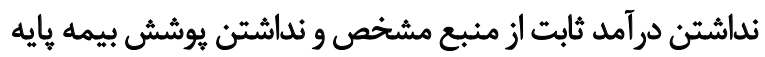

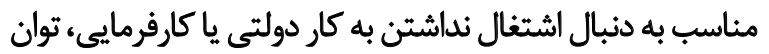

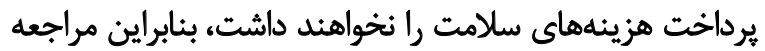
آنها براى دريافت خدمات كمتر بود.

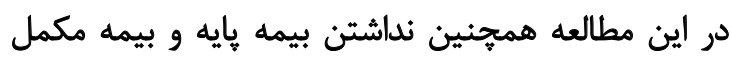

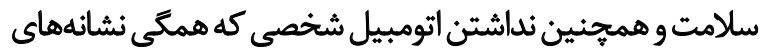

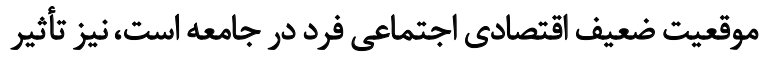

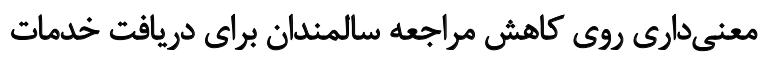

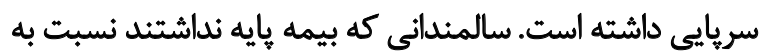

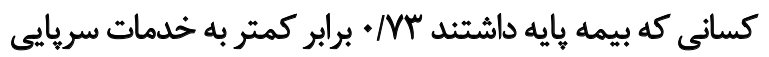

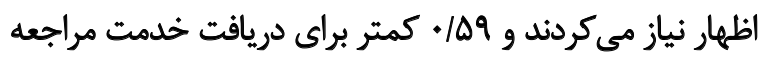

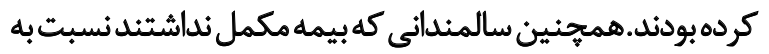

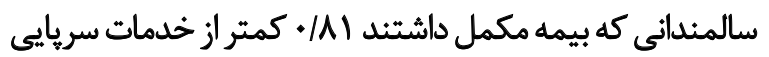

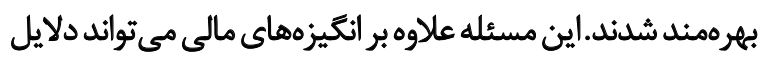

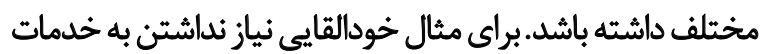

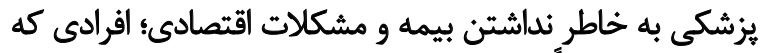

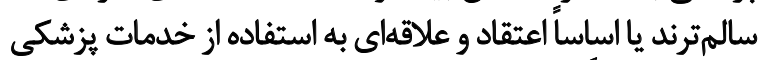

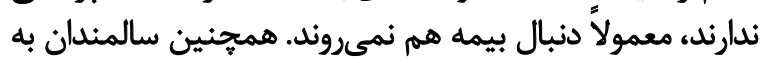

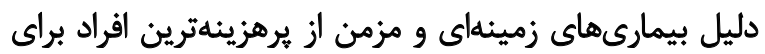

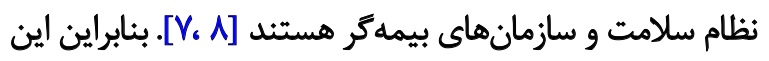

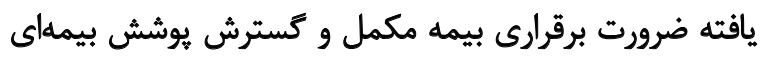

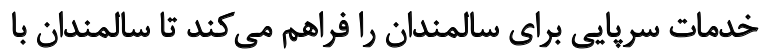

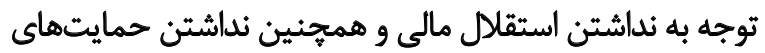

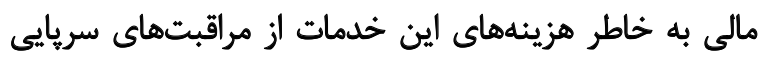
بعبهره نشوند و كيفيت زندكى إياينى را تجربه نكنيند.

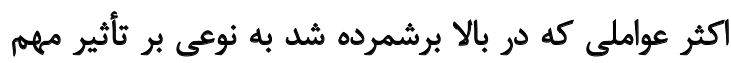

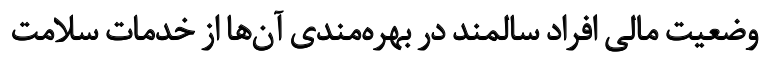

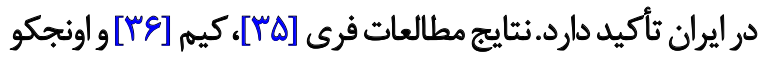

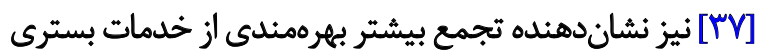

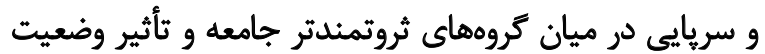

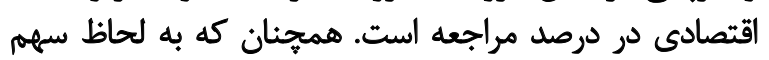

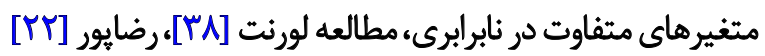

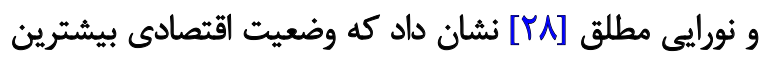

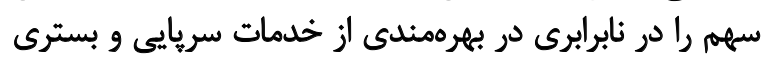

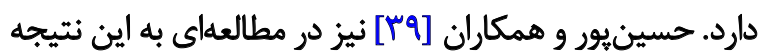

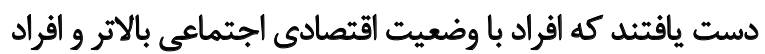

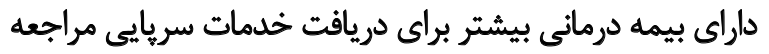

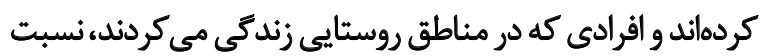

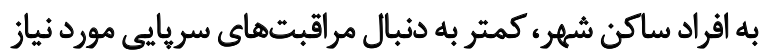

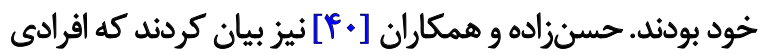

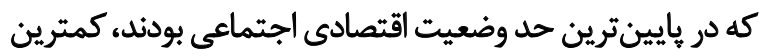

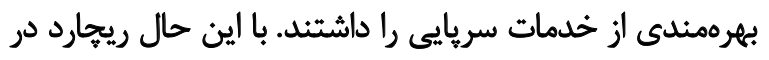


در زمينه اينكه اين افراد از جه نوع خدمات بهاداشتي درمانى

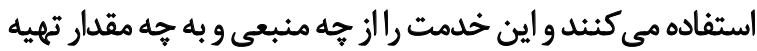

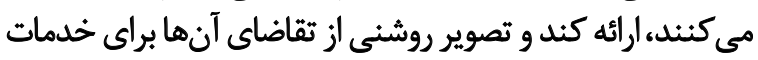

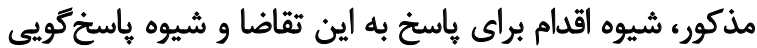

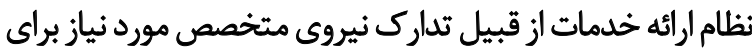

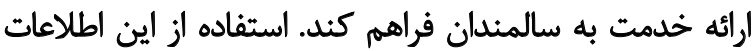

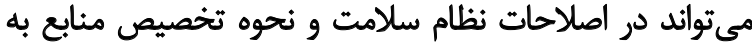

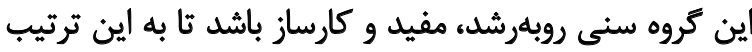

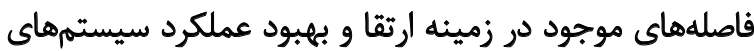

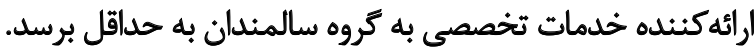

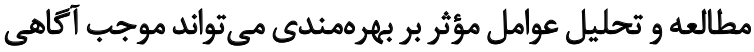

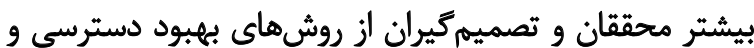
بهرهمندى افراد از خدمات سلامت شود.

اين مطالعه نشان داد كه با وجود اينكه زنان، مسنترها،

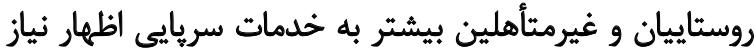

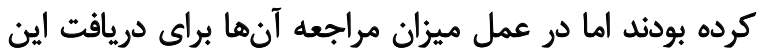

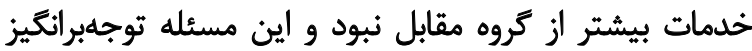

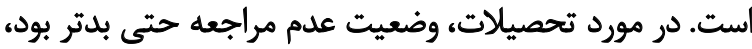

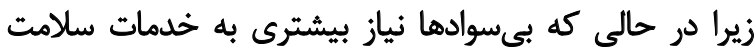

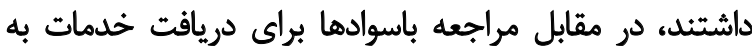

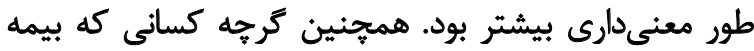

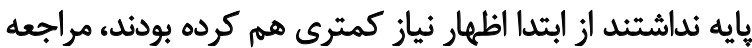

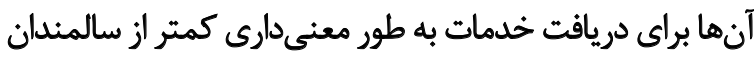

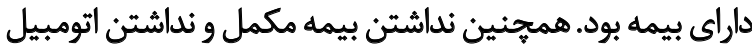

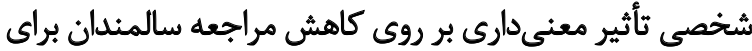

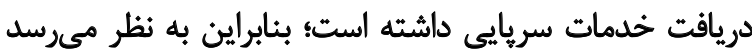

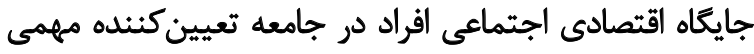

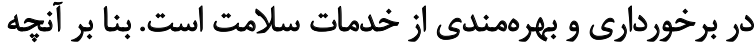

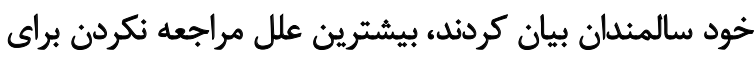

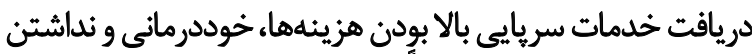

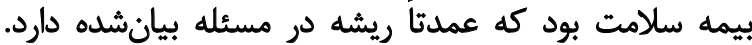

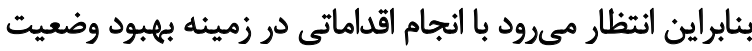

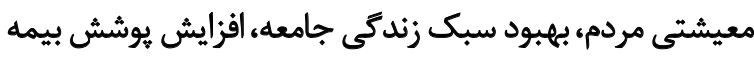

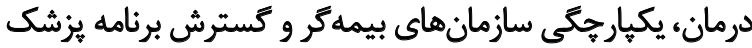

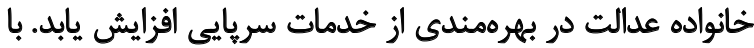

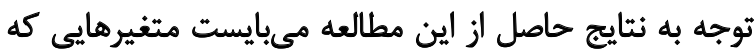

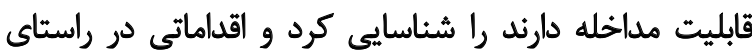

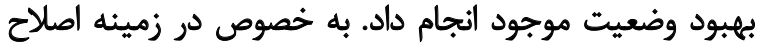

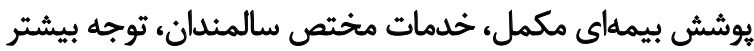

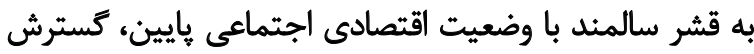

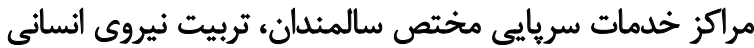

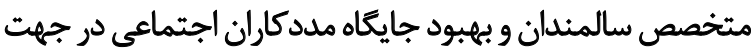

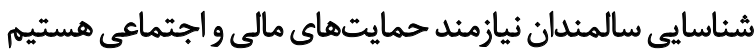

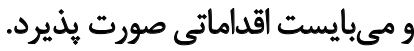

و بـا شرايط جديد و مشكلات بي بيشآمده بـا انعطاف بيشترى

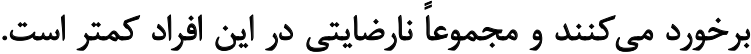

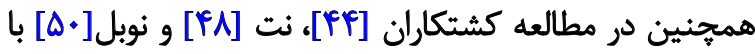
بالارفتن سطح تحصيلات نيز از ميزان رضايت كاسته دانه شده است

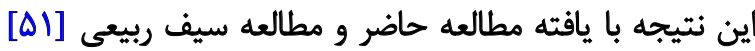

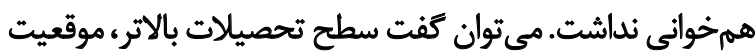

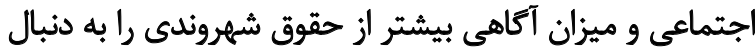

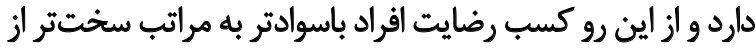

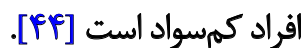

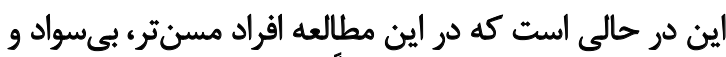

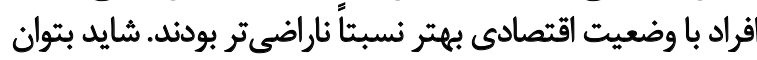

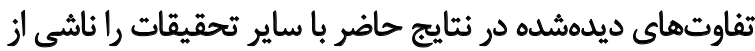

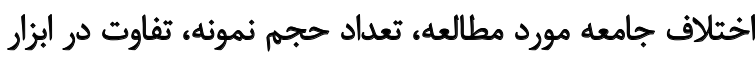

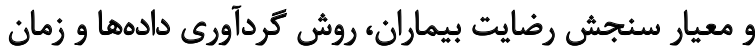

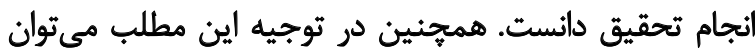

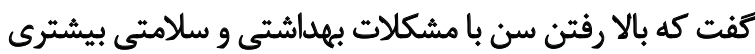

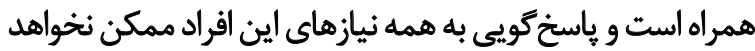

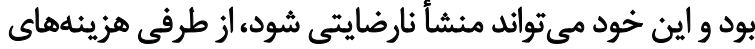

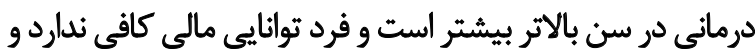

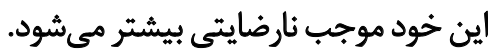

از محدوديتهاى مطالعه مي توان به اين مورد اشاره كرد كه

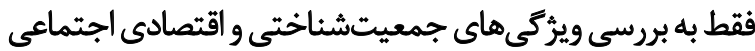

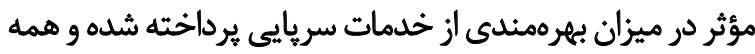

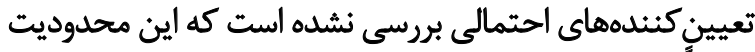

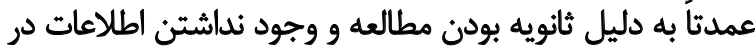

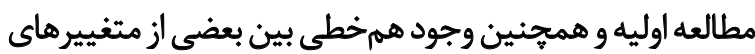

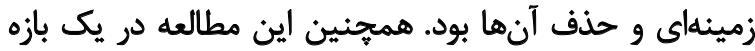

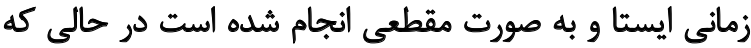

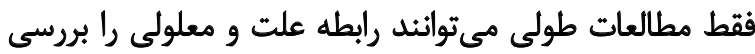

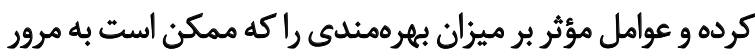

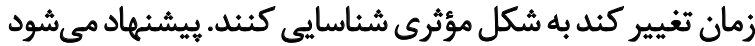

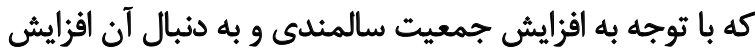

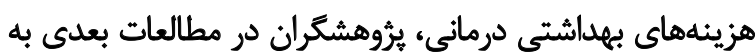

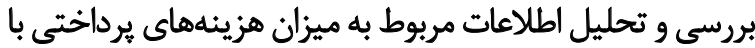
توجه به خدمات دريافتشده بيردازئد.

\section{تثيجهيَيرى نهبايى}

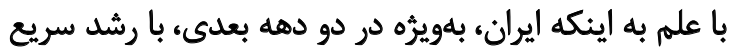

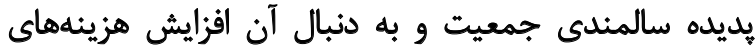

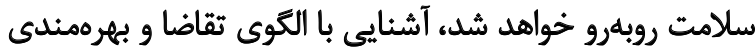

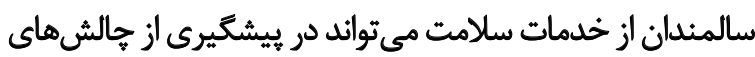

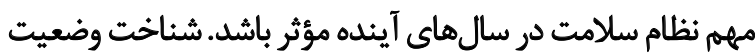

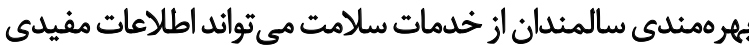


مالاحظات اخلاقى

يميروى از الصول الخاق يثوهش

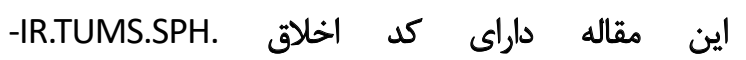

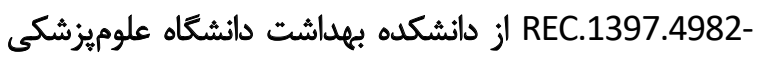

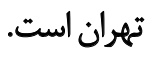

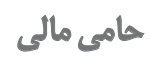

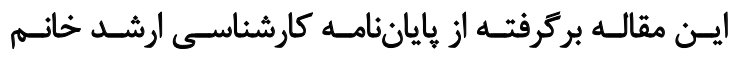

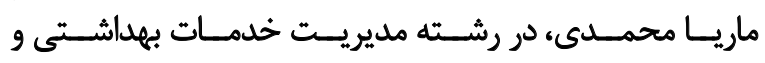

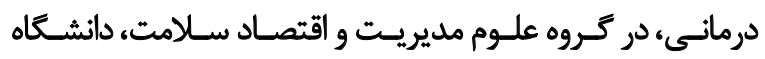

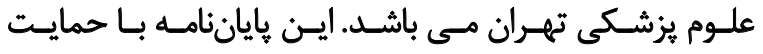

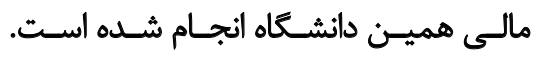

$$
\text { مشاركت ثويسند مكان }
$$

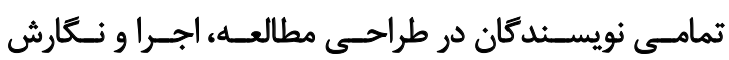

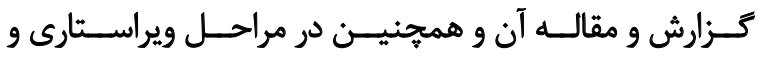

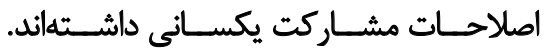

$$
\text { تعارض مثاقع }
$$

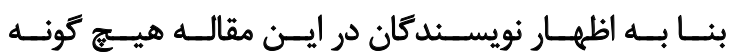

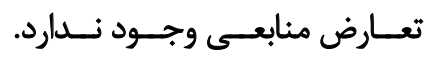

$$
\text { تشكر و قدردافي }
$$

بدينوسيله از دانشكده بهداشت براى حمايت مادى و معنوى

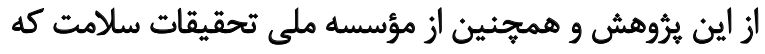

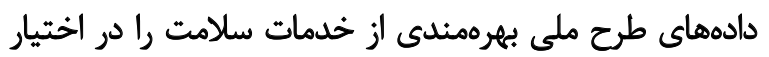
يُروهشكران قرار دادند تقدير و تشكر مي كنيم. 


\section{References}

[1] Yavari K, Basakha M, Sadeghi H, Naseri A. [Economic aspects of ageing (Persian)]. Iranian Journal of Ageing. 2015; 10(1):92-105. http:// salmandj.uswr.ac.ir/article-1-702-en.html

[2] Mirzaie M, Darabi S. [Population aging in iran and rising health care costs (Persian)]. Iranian Journal of Ageing. 2017; 12(2):156-69. [DOI:10.21859/sija-1202156]

[3] United Nations. World population ageing [Internet]. 2015 [Updated 2015]. Available from: https://www.un.org/en/development/desa/population/publications/pdf/ageing/WPA2015 Report.pdf

[4] Nikookar R, Ghaffari Sh, Akbari Kamrani AA, Sahaf R, Moghadam M, Ghadimi MR. [Assessing the duration of unnecessary hospitalization and expenses in older individuals suffering from cerebral vascular accident in the chronic care unit (Persian)]. Iranian Journal of Ageing. 2015; 10(2):180-7. http://salmandj.uswr. ac.ir/article-1-819-en.html

[5] Culyer AJ. The dictionary of health economics. United Kingdom: Edward Elgar Publishing; 2010. [DOI:10.4337/9781849806626]

[6] Norheim OF, Asada Y. The ideal of equal health revisited: definitions and measures of inequity in health should be better integrated with theories of distributive justice. International Journal for Equity in Health. 2009; 8:40. [DOI:10.1186/1475-9276-8-40] [PMID] [PMCID]

[7] Pavot W, Diener E. The satisfaction with life scale and the emerging construct of life satisfaction. The Journal of Positive Psychology. 2008; 3(2):137-52. [DOI:10.1080/17439760701756946]

[8] Soltani MH, Sahaf R, Mohammadi Shahbolaghi F, Ghaffari S, Khosravi A, Gohari MR. [Elderly, duration of hospitalization and hospital cost in Milad hospital in Iran (Persian)]. Iranian Journal of Ageing. 2012; 6(S1):58-65. http://salmandj.uswr.ac.ir/article1-489-en.html

[9] Schofield DJ, Earnest A. Demographic change and the future demand for public hospital care in Australia, 2005 to 2050. Australian Health Review. 2006; 30(4):507-15. [DOI:10.1071/AH060507] [PMID]

[10] Holtz C. Global health care: Issues and policies. $2^{\text {th }}$ ed. United States: Jones \& Bartlett Learning; 2013. https://books.google. $\mathrm{com} /$ books?id=PS0C2EuedncC $\&$ printsec $=$ frontcover\&source $=\mathrm{g}$ bs_ge_summary_r\&cad $=0 \# v=$ onepage\& $q \& f=$ false

[11] Poor Reza A, Khabiri Nemati R. [Health economics and aging (Persian)]. Salmand: Iranian Journal of Ageing. 2007; 1(2):80-7. http:// salmandj.uswr.ac.ir/article-1-17-en.html

[12] Yahyavi Dizaj J, Tajvar M, Mohammadzadeh Y, Marioryad H. [The effect of the presence of an elderly member on health care costs of Iranian households (Persian)]. Salmand: Iranian Journal of Ageing. 2020; 14(4):462-77. [DOI: 10.32598/sija.13.10.420]

[13] Pourreza A, Khabiri R, Arab M, Sari A, Rahimi A, Tal A. [Behavior and its influencing factors in search of the inhabitants of Tehran (Persian)]. Journal of the School of Public Health and Institute of Public Health Research. 2009; 7(2):1-13. http://sjsph.tums. ac.ir/article-1-112-en.html

[14] Saberian M, Haji Aghajani S, Ghorbani R. [Study of the mental status of the elderly and its relationship with leisure time activities (Persian)]. Journal of Sabzevar University of Medical Sciences. 2004; 10(4):53-60. https://www.sid.ir/en/Journal/ViewPaper. aspx?ID $=56437$
[15] Keshtkar AA, Ranjbaran M, Soori H, Etemad K, Khashayar P, Dini $\mathrm{M}$, et al. [Is the relationship between individual-and familylevels socioeconomic status with disease different? Analyzing third stage data of IMOS (Persian)]. Koomesh. 2015; 17(1):27-36. http:/ / koomeshjournal.semums.ac.ir/article-1-2663-en.html

[16] Borhaninejad VR, NaghibzadehTahami A, Nabavi H, Rashedi V, Yazdi-Feyzabadi V. [The utilization of health services and its influences among elderly people in Kerman-2014 (Persian)]. Journal of North Khorasan University of Medical Sciences. 2015; 7(2):229-40. [DOI:10.29252/jnkums.7.2.229]

[17] Gholami M, Nasiripoor AA, Maleki MR. [The relation between social determinant of health with access to health services in Gonbad kavoos (Persian)]. Community Health. 2016; 3(1):54-65. https:/ / www.sid.ir/en/journal/ViewPaper.aspx?id=508874

[18] Tajik F, Ferdosi M, Rajalian F. [Determining the socio-economic inequalities in health services utilization among ischemic heart disease patients; Case of Falavarjan city (Persian)]. Health Research Journal. 2016; 2(1):9-16. [DOI:10.18869/acadpub.hrjbaq.2.1.9]

[19] Costa MF, Ciosak SI. Atenção integral na saúde do idoso no Programa Saúde da Família: Visão dos profissionais de saúde. Revista da Escola de Enfermagem da USP. 2010; 44(2):437-44. [DOI:10.1590/S0080-62342010000200028].

[20] Ghadamgahi H B, Norouzi K, Mohammadi F, jandaqhi J. [Stauts and determiants of health services utilization among elderly rural hubitants in the Iraninan population (Persian)]. Koomesh. 2018; 20(4):779-85. http://koomeshjournal.semums.ac.ir/ article-1-4184-en.html

[21] Safari F, Nikravan A. [The effect of Socioeconomic factors and unmet needs on outpatient services in Iran (Persian)]. Journal of Health Administration. 2019; 22(1):91-102. http://jha.iums.ac.ir/ article-1-2897-en.html

[22] Rezapoor A, Roumiani Y, Azar FE, Ghazanfari S, Mirzaei S, Asiabar AS, et al. [Effective factors on utilization and access to health care: A population-based study in Kerman (Persian)]. Journal of Health Administration. 2015; 18(60):24-36. http://jha.iums.ac.ir/ article-1-1636-en.html

[23] Braveman P. Health disparities and health equity: concepts and measurement. Annual Review of Public Health. 2006; 27:167-94. [DOI:10.1146/annurev.publhealth.27.021405.102103] [PMID]

[24] Madyaningrum E, Chuang YC, Chuang KY. Factors associated with the use of outpatient services among the elderly in Indonesia. BMC Health Services Research. 2018; 18:707. [DOI:10.1186/ s12913-018-3512-0.] [PMID] [PMCID]

[25] George PP, Heng BH, Molina JA, Wong LY, Lin NC, Cheah JT. Self-reported chronic diseases and health status and health service utilization--results from a community health survey in Singapore. International Journal for Equity in Health. 2012; 11:44 [DOI:10.1186/1475-9276-11-44] [PMID] [PMCID]

[26] Ng N, Hakimi M, Santosa A, Byass P, Wilopo SA, Wall S. Is self-rated health an independent index for mortality among older people in Indonesia?. PLoS One. 2012; 7(4):e35308. [DOI:10.1371/ journal.pone.0035308] [PMID] [PMCID]

[27] Hashemi N. [Examining the views of the elderly regarding the provision of some health care services to the elderly (Persian)] [PhD. dissertaion]. Isfahan: Isfahan University of Medical Sciences; 2012. http:/ /elib.mui.ac.ir/site/catalogue/96934 
[28] Nooraiee Motlagh S, Saber Mahani A, Barooni M, Asadi Lari M, Vaez Mahdavi MR, Hadian M. [Determining Factors related to health services utilization (Persian)]. Razi Journal of Medical Sciences. 2015; 21(127):61-72. http://rjms.iums.ac.ir/article1-3475-en.html

[29] Joulaei H, Bhuiyan AR, Sayadi M, Morady F, Kazerooni PA. Slums' access to and coverage of primary health care services: A cross-sectional study in shiraz, a metropolis in southern Iran. Iranian Journal of Medical Sciences. 2014; 39(Suppl 2):184-90. https://www.ncbi.nlm.nih.gov/pmc/articles/PMC3993042/

[30] Aliakbari Saba R, Safakish M. [Utilization of health services in the country of Iran (Persian)]. Journal of Amar. 2015; 16:9-16.

[31] Wagstaff A, Paci P, Van Doorslaer E. On the measurement of inequalities in health. Social Science \& Medicine. 1991; 33(5):54557. [DOI:10.1016/0277-9536(91)90212-U]

[32] Park JM. Health status and health services utilization in elderly Koreans. International Journal for Equity in Health. 2014; 13:73. [DOI:10.1186/s12939-014-0073-7] [PMID] [PMCID]

[33] Bayati M, Akbarian R, Kavosi Z, Sadraei Javaheri A, Amini Rarani M, Delavari S. [Socio-economic determinants of health in the western Pacific: A combined data analysis (Persian)]. Social Welfare Quarterly. 2013; 12(47):111-30. http://refahj.uswr.ac.ir/ article-1-1125-fa.html

[34] Manski RJ, Moeller JF, Chen H, Schimmel J, Clair PA, Pepper JV. Patterns of older Americans' health care utilization over time. American Journal of Public Health. 2013; 103(7):1314-24. [DOI:10.2105/AJPH.2012.301124] [PMID] [PMCID]

[35] Ferry GA, Dickson SR, Mbaruku G, Freedman LP, Kruk ME. Equity of inpatient health care in rural Tanzania: A population-and facility-based survey. International Journal for Equity in Health. 2012; 11:7. [DOI:10.1186/1475-9276-11-7] [PMID] [PMCID]

[36] Kim CW, Lee SY, Hong SC. Equity in utilization of cancer inpatient services by income classes. Health Policy. 2005; 72(2):187-200. [DOI:10.1016/j.healthpol.2004.03.009] [PMID]

[37] Onwujekwe O, Onoka C, Uzochukwu B, Hanson K. Constraints to universal coverage: Inequities in health service use and expenditures for different health conditions and providers. International Journal for Equity in Health. 2015; 10:50. [DOI:10.1186/14759276-10-50] [PMID] [PMCID]

[38] Lorant V, Boland B, Humblet P, Deliège D. Equity in prevention and health care. Journal of Epidemiology \& Community Health. 2002; 56(7):510-6. [DOI:10.1136/jech.56.7.510] [PMID] [PMCID]

[39] Hosseinpoor AR, Naghavi M, Alavian SM, Jamshide H, Vega J, Speybroeck N. [Determinants of seeking needed outpatient care in Iran: results from a national health services utilization survey (Persian)]. Archives of Iranian Medicine. 2007; 10(4):439 -45. https:/ / www.sid.ir/en/journal/ViewPaper.aspx?ID=89354

[40] Hassanzadeh J, Mohammadbeigi A, Eshrati B, Rezaianzadeh A, Rajaeefard A. Determinants of inequity in health care services utilization in Markazi Province of Iran. Iranian Red Crescent Medical Journal. 2013; 15(5):363-70. [DOI:10.5812/ircmj.3525] [PMID] [PMCID]

[41] Richard J, John F, Patricia A, John V. Patterns of older americans' health care utilization over time. American Journal of Public Health 2013; 103(7):1314-24. [DOI:10.2105/AJPH.2012.301124]
[42] Nie JX, Wang L, Tracy CS, Moineddin R, Upshur RE. Health care service utilization among the elderly: Findings from the Study to Understand the Chronic Condition Experience of the Elderly and the Disabled (SUCCEED project). Journal of Evaluation in Clinical Practice. 2008; 14(6):1044-9. [DOI:10.1111/j.13652753.2008.00952.x] [PMID]

[43] Morishita L, Boult C, Boult L, Smith S, Pacala JT. Satisfaction with outpatient geriatric evaluation and management (GEM). The Gerontologist. 1998; 38(3):303-8. [DOI:10.1093/geront/38.3.303] [PMID]

[44] Keshtkaran A, Heidari AR, Keshtkaran V, Taft V, Almasi A. [Satisfaction of outpatients referring to teaching hospitals clinics in Shiraz, 2009 (Persian)]. Payesh (Health Monitor). 2012; 11(4):459-65. http:/ / payeshjournal.ir/article-1-440-en.pdf

[45] Bakhtiari AH, Hadj-Hasani AH. [The effective parameters on the patient satisfaction level of the referral patients to the outpatient physiotherapy clinics of the Semnan medical sciences university (second half of the year 2001) (Persian)]. Koomesh. 2005; 6(2):167-74. http://koomeshjournal.semums.ac.ir/article1-156-en.html

[46] Jackson JL, Chamberlin J, Kroenke K. Predictors of patient satisfaction. Social Science \& Medicine. 2001; 52(4):609-20. [DOI:10.1016/S0277-9536(00)00164-7]

[47] Bodur S, Özdemir YE, Kara F. Outpatient satisfaction with health centers in urban areas. Turkish Journal of Medical Sciences. 2002; 32(5):409-14. https://journals.tubitak.gov.tr/medical/ abstract.htm?id=5798

[48] Net N, Sermsri S, Chompikul J. Patient Satisfaction toward health services at the out-patient department clinic of wangnumyen community hospital, Sakaeo province. Thailand: Mahidol University; 2007.

[49] Amerion A, Ebrahimnia M, Karimi Zarchi A, Tofighi Sh, Zaboli $\mathrm{R}$, Rafati $\mathrm{H}$. [Inpatient and outpatient satisfaction of a military hospital (Persian)]. Journal of Military Medicine. 2009; 11(1):3744. http:// militarymedj.ir/article-1-606-en.html

[50] Nobile CG, Nicotera G, Grillo T, Pavia M. Satisfaction with care in outpatient clinics in Italy. Journal of Preventive Medicine and Hygiene. 2004; 45:35-9. https:/ /www.iris.unicz.it/handle/20.500 $.12317 / 6940$ ? mode $=$ full. 19

[51] Seyf RM, Shahidzadeh MA. [Patient satisfaction: A study of Hamedan teaching and general hospitals (Persian)]. Payesh. 2006; 5(4):271-9. https://www.sid.ir/en/journal/ViewPaper. aspx?id=69933 